\title{
Proceedings of the 2011 National Toxicology Program Satellite Symposium
}

\author{
Gary Boorman ${ }^{1}$, Torrie A. Crabbs ${ }^{2}$, Holly Kolenda-Roberts ${ }^{2}$, Ken Latimer ${ }^{1}$, Andrew D. \\ Miller $^{3}$, Kathleen B. Muravnick ${ }^{4}$, Abraham Nyska ${ }^{5}$, Ricardo Ochoa ${ }^{6}$, Ingrid D. Pardo ${ }^{7}$, Yuval \\ Ramot $^{8}$, Deepa B. Rao ${ }^{9}$, JoAnn Schuh ${ }^{10}$, Andrew Suttie ${ }^{1}$, Greg S. Travlos ${ }^{11}$, Jerrold M. \\ Ward $^{12}$, Jeffrey C. Wolf ${ }^{13}$, and Susan A. Elmore ${ }^{11}$ [Chair] \\ ${ }^{1}$ Covance Laboratories, Inc., Chantilly, Virginia, USA
}

${ }^{2}$ Experimental Pathology Laboratories, Inc., Research Triangle Park, North Carolina, USA

${ }^{3}$ New England Primate Research Center, Harvard Medical School, Southborough, Massachusetts, USA

${ }^{4}$ Tufts Cummings School of Veterinary Medicine, North Grafton, Massachusetts, USA

${ }^{5}$ Consultant in Toxicological Pathology, Timrat, and Sackler School of Medicine, Tel Aviv University, Tel Aviv, Israel

${ }^{6}$ Pre-Clinical Safety Inc., Niantic, Connecticut, USA

${ }^{7}$ Pfizer Inc., Groton, Connecticut, USA

${ }^{8}$ Hadassah-Hebrew University Medical Center, Jerusalem, Israel

${ }^{9}$ Integrated Laboratory Systems, Inc., Research Triangle Park, North Carolina, USA

${ }^{10} \mathrm{JCL}$ Schuh, PLLC, Bainbridge Island, WA and Biological Test Center, Irvine, California, USA

${ }^{11}$ National Toxicology Program, National Institute of Environmental Health Sciences, National Institutes of Health, Research Triangle Park, North Carolina, USA

${ }^{12}$ Global VetPathology and NIAID, NIH, Maryland, USA

${ }^{13}$ Experimental Pathology Laboratories, Inc., Sterling, Virginia, USA

\begin{abstract}
The 2011 annual National Toxicology Program (NTP) Satellite Symposium, entitled "Pathology Potpourri," was held in Denver, Colorado in advance of the Society of Toxicologic Pathology's 30th Annual Meeting. The goal of the NTP Symposium is to present current diagnostic pathology or nomenclature issues to the toxicologic pathology community. This article presents summaries of the speakers' presentations, including diagnostic or nomenclature issues that were presented, along with select images that were used for audience voting or discussion. Some lesions and topics covered during the symposium include: proliferative lesions from various fish species including ameloblastoma, gas gland hyperplasia, nodular regenerative hepatocellular hyperplasia, and malignant granulosa cell tumor; spontaneous cystic hyperplasia in the stomach of CD1 mice and histiocytic aggregates in the duodenal villous tips of treated mice; an olfactory neuroblastoma in a
\end{abstract}

\footnotetext{
Copyright $\odot 2012$ by The Author(s)

Address correspondence to: Susan A. Elmore, National Toxicology Program, Cellular and Molecular Pathology Branch, National Institute of Environmental Health Sciences, National Institutes of Health, Research Triangle Park, NC 27709, USA; elmore@niehs.nih.gov.

The authors declared no potential conflicts of interests with respect to the authorship and/or publication of this article.
} 
cynomolgus monkey; various rodent skin lesions, including follicular parakeratotic hyperkeratosis, adnexal degeneration, and epithelial intracytoplasmic accumulations; oligodendroglioma and microgliomas in rats; a diagnostically challenging microcytic, hypochromic, responsive anemia in rats; a review of microcytes and microcytosis; nasal lesions associated with green tea extract and Ginkgo biloba in rats; corneal dystrophy in Dutch belted rabbits; valvulopathy in rats; and lymphoproliferative disease in a cynomolgus monkey.

\section{Keywords}

NTP Satellite Symposium; ameloblastoma; gas gland hyperplasia; stomach cystic hyperplasia; sodium dichromate dihydrate; olfactory neuroblastoma; cynomolgus monkey; adnexal degeneration; parakeratotic hyperkeratosis; oligodendroglioma; microglioma; microcytic hypochromic anemia; microcytosis; spherocytosis; poikilocytosis; green tea; Ginkgo biloba; corneal dystrophy; Dutch belted rabbit valvulitis; valvulopathy; post-transplant lymphoproliferative disease

\section{Introduction}

The National Toxicology Program (NTP) Satellite Symposium is a one-day meeting that is traditionally held in conjunction with the annual Society of Toxicologic Pathology (STP) meeting (Adams et al. 2011; Bach et al. 2010). Attendance at the Symposium has steadily increased since the first meeting in 2000, and this year, there were 230 registered participants. The objective of this annual symposium is to provide continuing education on interpreting histopathology slides, including the presentation and discussion of diagnostically difficult, interesting, or rare lesions and challenging nomenclature issues. The session is interactive in that each speaker presents images for audience voting via wireless keypads. Once the votes are tallied, the results are displayed on the screen for all to view. The speaker generally provides his or her preferred diagnosis for comparison with some additional background information, after which lively and productive discussion ensues.

The theme for the 2011 Symposium was "pathology potpourri," which allowed for a variety of topics to be presented. Species included the rat, mouse, monkey, fish, and rabbit. Organ systems included gastrointestinal, brain, skin, nose, eye, heart, and blood. A clinical pathology case involving microcytosis and a review of several acquired and hereditary conditions that may cause microcytosis was subsequently presented. This article provides synopses of all presentations including the diagnostic or nomenclature issues, a selection of images presented for voting and discussion, voting choices, voting results, and major discussion points.

\section{Bouillabaisse: A Sumptuous Medley of Proliferative Fish Lesions}

The symposium started off with presentations given by Dr. Jeffrey Wolf (Experimental Pathology Laboratories, Inc., Sterling, VA, USA) featuring four cases of proliferative lesions in various types of fish that stumped many of the participants, most of whom had very little experience in the area of fish pathology. The initial case consisted of a series of oral growths (Figure 1A) in captive two- to three-year-old Chinook salmon (Oncorhynchus tshawytscha) originally collected as juveniles from tributaries of the Snake River in Oregon and Idaho, USA. Microscopically (Figures 1B-1D), the growths were composed of sheets and cords of polygonal cells that extended deep from the oral mucosal surface or branched off the outer dental epithelium of tooth root sulci. Additional characteristics of the proliferative tissue included acantholysis; a tendency to form crevices or clefts; and at high magnification, evidence of intercellular bridges (desmosomal attachments). The five voting 
choices presented to the audience were (1) inverted papilloma, (2) squamous cell carcinoma, (3) ameloblastoma, (4) odontoma, and (5) basal cell carcinoma. The most popular answer from the participants, ameloblastoma (34\% of respondents), was consistent with the previously published diagnosis of this epizootic neoplastic disorder (Grim at al. 2009). Gross photographs demonstrated the pattern of neoplastic formation, as the tumors progressed from linear red plaques located in the vicinity of the dental lamina, to large, irregular masses that disfigured the mouth and lips. The ensuing discussion involved potential etiologies of ameloblastomas in Pacific salmon, including viral, toxic, and genetic causes. A virally induced neoplastic disorder seems to be the most plausible explanation; however, despite the presence of ultrastructurally evident, viral-like particles in one specimen, the definitive cause of the lesions has not been established.

The second case of this presentation was an intra-abdominal mass from an Atlantic spadefish (Chaetodipterus faber). The mass consisted of a core of necrotic and inflammatory debris, which was enveloped by dense fibrovascular tissue (Figure 1E). External to the fibrovascular tissue was an irregular layer of well-vascularized, pale pink, polygonal cells that formed lobular sheets, and the sheets were in turn surrounded by discrete fingers and islands of capillary vascular tissue (Figure 1F). Diagnostic options offered to the participants were (1) ganglioneuroblastoma, (2) hepatocellular carcinoma and hemangiosarcoma (collision tumor), (3) gas gland adenocarcinoma, (4) gas gland hyperplasia, and (5) keratoacanthoma. The two answers favored by the participants were hepatocellular carcinoma and hemangiosarcoma (43\%) and gas gland adenocarcinoma (37\%), but only 5\% of participants concurred with the presenter's diagnosis of gas gland hyperplasia. Participants were shown images of the normal gas gland and rete mirabile of the swim bladder. Among various fishes, the gas gland functions as a buoyancy apparatus, and a device for the detection of sound waves or pressure changes, the generation of sounds, and oxygen respiration. Discussion then focused on morphologic differences between gas gland hyperplasia (simple increase in glandular tissue), gas gland adenoma (nodular masses usually composed of primarily epithelial tissue), and gas gland adenocarcinoma (haphazard arrangement of epithelial and/or vascular tissue, with or without pronounced cellular atypia). The current case had been considered most consistent with hyperplasia because the proliferative tissue, which was centered around intense swim bladder inflammation, did not display evidence of disorganization, mass-like growth, or atypical cellular features (Fournie et al. 1999). The presenter then described a progressive syndrome that he had witnessed on occasion in Japanese medaka (Oryzias latipes), in which skeletal deformities were associated with anomalous patency of the pneumatic duct, the latter of which led to swim bladder infection, reactive gas gland hyperplasia, and eventually, gas gland neoplasia.

The subject of the third case was an adult Japanese medaka that had been exposed to a pharmaceutical compound by the water bath route from day 71 to day 100 post-hatch. The abdominal cavity of this particular fish, which was from the high-dose group, was almost entirely occupied by a large, multinodular mass that displaced the viscera caudally. At high magnification, the nodular areas consisted of hepatocyte-like cells with substantial cellular atypia, cells that formed primitive bile ducts, and palisading oval cells (Figures 1G-1I). Single-cell apoptotic necrosis and binucleate hepatocytes were clearly apparent in one image (Figure 1J). The diagnostic choices included (1) hepatocholangiocarcinoma, (2) oval cell carcinoma, (3) cholangiocarcinoma, (4) hepatocellular carcinoma, and (5) nodular regenerative hepatocellular hyperplasia. The answer most favored by participants was hepatocholangiocarcinoma (45\%). In contrast, the presenter's diagnosis of nodular regenerative hepatocellular hyperplasia garnered only $7 \%$ of the votes.

The participants were then shown a series of images that illustrated the progression of lesions among various fish from different dose groups of the same toxicological study. In 
fish exposed to low concentrations of the compound, a slight rounding of the liver margin was apparent at low magnification, whereas a high-magnification view revealed occasional megalocytosis and increased numbers of bi- and trinucleate hepatocytes. In contrast, changes present in fish from the medium-dose group included obvious nodular distortion of the liver profile, in addition to profound anisocytosis, anisokaryosis, multinucleated hepatocytes, and oval cell and bile duct proliferation. The reasons cited by the presenter for his diagnosis of regenerative hyperplasia rather than carcinoma for the severely affected fish included:

a. The capacity of the fish liver to regenerate is far greater than the mammalian liver. For example, in cases of massive hepatocellular necrosis, the livers of surviving fish can recover completely in a matter of weeks (Wolf and Wolfe 2005).

b. Compound exposure resulted in a continuous, dose-dependent progression of lesions, from minimal to severe, without any distinct break point to suggest neoplastic transformation. Notably, six of the seven surviving high-dose fish had hepatic lesions that were graded as severe.

c. There was ongoing cytotoxicity at sacrifice, as evidenced by the presence of individual cell apoptotic necrosis.

d. The livers of medium- and high-dose fish had proliferations of mutipotent precursor cells (oval cells, "bile preductular epithelial cells") that are typically associated with regenerative liver repair in fish.

e. Hyperplasia represented the more conservative diagnosis for a study in which there was no conclusive morphologic evidence of tumor malignancy (e.g., local tissue invasion or distant metastasis), and no recovery sacrifice.

However, the presenter indicated that he would likely have rendered a diagnosis of carcinoma if he had received only a single fish with severe lesions, and did not have the broader perspective provided by evaluating the entire study.

The fourth and final case in this presentation was an intra-abdominal mass from a wildcaught, adult longjaw mudsucker (Gillichthys mirabilis). Microscopically, the mass was characterized by proliferations of haphazardly arranged, angular cells within a dense, collagenous matrix (Figure 1K). The proliferating cells had abundant amphophilic cytoplasm; eccentric, bizarre, and often megakaryocytic nuclei; and frequent aberrant mitotic figures (Figure 1L). Additionally present within the mass was a cyst-like structure that, at low magnification, appeared to contain numerous spherical basophilic bodies. As a hint to the tissue of origin, the participants were shown an image of the same type of organ (also abnormal, however) from another of the submitted mudsuckers. The diagnostic choices were (1) malignant granulosa cell tumor, (2) malignant astrocytoma, (3) rhabdomyosarcoma, (4) glioblastoma multiforme, and (5) ultimobranchial gland adenocarcinoma. Only $17 \%$ of respondents selected the presenter's diagnosis of malignant granulosa cell tumor, whereas the diagnosis with the greatest number of votes was ultimobranchial gland adenocarcinoma (44\%). The participants were again shown the hint slide, which contained several perinucleolar-stage oocytes within an ovary that was otherwise effaced by microsporidian xenomas (cyst-like structures) that were surrounded by proliferating (hyperplastic) granulosa cells. The mudsuckers had been collected as part a field study (Vidal-Dorsch et al. 2011). In a number of the collected females, histopathologic examination revealed that the ovaries contained microsporidian xenomas, the presence of which appeared to induce intense granulosa cell hyperplasia. In the case presented to the participants, it appeared that the neoplastic transformation of granulosa cells had possibly occurred as a sequel to the microsporidia-induced hyperplasia. 


\section{Lesions in the Stomach and Duodenum of the Mouse}

Dr. Andrew Suttie, in collaboration with Dr. Gary Boorman (Covance Laboratories, Chantilly, VA, USA), presented two lesions, the first from the glandular stomach of a CD1 mouse and the second from the duodenum of a B6C3F1 mouse. The stomach lesion (Figure 2A-2D) was a focal proliferative lesion involving all of the glandular stomach. The symposium participants were asked to vote on a number of diagnoses: cystic hyperplasia, dysplasia, carcinoid, adenoma, and carcinoma. The vote was overwhelming for cystic hyperplasia (67\%). Dr. Suttie then presented a series of slides showing the range of severity of this proliferative lesion seen in control and treatment groups of CD1 mice on carcinogenicity studies ranging from a normal stomach through mild hyperplasia up to the cystic hyperplasia, of which further examples were shown. Hyperplasia involves all cell types and is seen diffusely throughout the glandular stomach with the mucosa-forming rugae. As the lesion progresses, cystic spaces become prominent, sometimes with mineralization, inflammation, and herniation of cysts into the muscularis externa. These cysts are lined by either simple or metaplastic epithelium that generally retains normal orientation. Local invasion beyond the muscularis or distant metastasis is not seen. Dr. Suttie noted that the most severe lesion has occurred with a single instance in each of three recent carcinogenicity studies and that it has not been seen as a treatment-related finding. Therefore, when hyperplasia occurs in treated groups, particularly the high-dose group, it should not be recorded as treatment related without other supporting evidence. Since it is not considered to be neoplastic, it should be graded along the full continuum of diffuse hyperplasia of the stomach mucosa. During the discussion, one audience member noted that he would prefer a diagnosis of adenoma, as did $11 \%$ of the voting audience. The presenter indicated that despite the extremely florid nature of the lesions, there was no supporting evidence (cellular atypia, metastases, etc.) for a malignant diagnosis.

Dr. Suttie's second lesion was from National Toxicology Program (NTP) studies on sodium dichromate dihydrate (SDD), which occurs as a groundwater contaminant. The lesion presented for voting showed accumulations of cells with foamy cytoplasm within the interstitium of the duodenal villus tips (Figures $2 \mathrm{E}$ and $2 \mathrm{~F}$ ). The symposium audience was asked to identify the cell type involved or diagnosis from the projected hematoxylin and eosin (H\&E) images. Voting choices were (1) macrophage/histiocyte aggregates, (2) mast cell aggregates, (3) fibroblast, and (4) proliferative enteritis. The majority vote for macrophage/histiocyte aggregates (53\%) agreed with the NTP diagnosis of histiocyte accumulation for this lesion. Dr. Suttie then presented images of other sites in which histiocyte accumulation was seen as a treatment-related effect in the SDD studies; the periportal region of the liver, in the medullary sinuses of mesenteric lymph nodes, and accompanying epithelial hyperplasia in the crypts and villi of the duodenum (Figures $2 \mathrm{G}$ and $2 \mathrm{H})$. Dr. Suttie pointed out that similar accumulations of histiocytes were observed in studies with some pharmaceuticals.

\section{A Kink in the Monkey's Neck}

The third presentation at the NTP Satellite Symposium was entitled "A Kink in the Monkey's Neck.” Dr. Ingrid Pardo (Pfizer, Inc., Groton, CT, USA), in collaboration with Dr. Kathleen Muravnick (Tufts Cummings School of Veterinary Medicine, North Grafton, MA, USA), presented a case of a five-year-old female cynomolgus monkey (Macaca fascicularis) with a mass in the base of the skull. This monkey presented with a clinical history of lethargy and anorexia. A neurologic examination revealed mild intention tremors, anisocoria, ataxia, and possible left-sided facial paralysis. At necropsy, there was a tan to gray, granular-appearing, soft, irregularly shaped mass that extended from the base of the skull at the level of the sella turcica, through the cribriform plate, to the upper areas of the 
nasal cavity and paranasal sinuses (Figure 3A). The tumor compressed the ventral aspect of the brain from the frontal lobes to the midbrain. Histologically, this infiltrative and nonencapsulated mass was composed of neoplastic cells arranged in solid clusters, sheets, and lobules that were separated by delicate fibrovascular connective tissue (Figure 3B). Tumor cells frequently formed true rosettes or pseudorosettes and had a primitive appearance (Figure 3C). Neoplastic cells had small, round to polygonal, hyperchromatic nuclei and scant eosinophilic cytoplasm. Mitotic figures, as well as large foamy cells (nasal clear cells), and areas of hemorrhage and necrosis were commonly observed throughout the mass.

After viewing several gross and histologic images, the audience was asked to vote on the best diagnosis for this tumor. The voting choices and results were: esthesioneuroblastoma (olfactory neuroblastoma; 53\%), lymphosarcoma (12\%), suprasellar germ cell tumor (11\%), meningioma (10\%), intracranial schwannosarcoma (7\%), and malignant pituitary gland tumor $(6 \%)$. The majority vote concurred with the speaker's diagnosis of olfactory neuroblastoma. Since olfactory neuroblastomas originate from the olfactory epithelium, much of the discussion following this presentation centered on the importance of hemisplitting the cranium along the midline into two sagittal half-sections to locate the starting point of the tumor in the nasal cavity with infiltration into the base of the cranial cavity.

Multiple immunohistochemical stains of this tumor were shown to the audience, including protein gene product 9.5 (PGP 9.5; neuron-specific protein), CD 56 (neuronal cell adhesion molecule), S-100, neuron-specific enolase (NSE), and vimentin (data not shown). The expression of PGP 9.5, CD 56, S-100, NSE, and vimentin, along with the gross and histopathologic findings, confirmed that this neoplasm was an olfactory neuroblastoma and ruled out other neoplasms such as malignant pituitary tumor, lymphosarcoma, meningioma, suprasellar germ cell tumor, and intracranial schwannosarcoma.

Olfactory neuroblastomas are uncommon neuroectodermal tumors that may arise within the nasal cavity (Mattix et al. 1994). The morphology of this neoplasm is heterogenous and the histogenic origin is unclear, resulting in many different names including, but not limited to, olfactory neuroblastoma, esthesioneuroblastoma, and olfactory neuroepithelioma (Cox and Powers 1989; Mattix et al. 1994). One article describing a prospective study in humans suggests that the term "olfactory neuroblastoma" might be the most reflective of both the origin and nature of the neoplasm (Lund et al. 2003). This neoplasm has been described in humans (Faragalla and Weinreb 2009), dogs (Mattix et al. 1994), rats (Garcia et al. 1970; Love et al. 1977), cats (Cox and Powers 1989), cows (Anderson and Cordy 1981; Haynes and Leininger 1984), horses (Yamate et al. 2006), and a cynomolgus monkey (Correa at al. 1975). Interestingly, olfactory neuroblastomas are chemically induced in rats (Long et al. 2003; Pelfrene and Garcia 1976) contrary to other animal species and humans where this tumor is typically of spontaneous origin. Some examples of chemicals that induce olfactory neuroblastomas in rats include 1-nitrosopiperazine and nitrosomorpholine (Garcia et al. 1970). The development of olfactory neuroblastomas in rats is not related to the route of administration of the chemical, but it is directly associated with chemical metabolism in nasal basal cells that leads to neoplastic transformation.

\section{My Skin Is Giving Me Problems}

Dr. Torrie Crabbs (Experimental Pathology Laboratories, Inc., Research Triangle Park, NC, USA), in collaboration with Dr. Deepa B. Rao (Integrated Laboratory Systems, Inc., Research Triangle Park, NC, USA), presented three cases. Each one highlighted a specific component of an array of skin lesions that had been discovered in B6C3F1 mice and Harlan Sprague Dawley (HSD) rats following subchronic (three-month) whole-body inhalation 
exposure to a compound under study by the NTP. In each case, the images presented were from the routine section of skin, which is that overlying the preputial glands.

The first case presentation was from a high-dose male $\mathrm{B} 6 \mathrm{C} 3 \mathrm{~F} 1$ mouse and focused on the epithelium, specifically that of the follicular infundibulum. Within this region, the epithelium was thickened and covered by a thick, compact layer of bright eosinophilic material. The material contained nuclei and often expanded the infundibulum (Figures 4A and 4B). The following voting choices were provided: (1) skin, epithelium - necrosis; (2) skin, epithelium - hyperkeratosis; (3) skin, epithelium - parakeratotic hyperkeratosis; (4) skin, follicle, epithelium - necrosis; (5) skin, follicle, epithelium — hyperkeratosis; and (6) skn, follicle, epithelium - parakeratotic hyperkeratosis. Given the folliculocentric nature of the lesion and the presence of nuclei within the material, the pathology working group (PWG) preferred diagnosis was that of "skin, follicle, epithelium - parakeratotic hyperkeratosis." The majority of the audience (62\%) agreed with this diagnosis.

The second case was from a male high-dose HSD rat and focused on the region of the midto deep dermis, specifically the folliculo-sebaceous units (Figures 4C and 4D). The lesion was characterized by the following features: irregular to distorted hair follicles (often in telogen phase); infundibular accumulations of pale basophilic to amphophilic debris; a decrease or lack of well-developed sebaceous glands; and the presence of increased pyknotic and/or karyorrhectic debris within the follicular epithelium and adnexal structures. The following voting choices were provided: (1) within normal limits; (2) follicular dysplasia; (3) follicular atrophy; (4) follicular degeneration; and (5) adnexal degeneration. The audience's favored diagnosis was that of adnexal degeneration (51\%), which concurred with the NTP's PWG vote.

This case stimulated considerable discussion from the audience. Questions ranged from whether or not a mechanism of action was known, to whether additional glands were affected, to whether a change in hair quality had been noted. Dr. Crabbs stated that although an exact mechanism of action was not known for this case, in humans a condensation reaction between this chemical and ammonia, in the presence of water, has been reported to occur. This reaction results in the production of a black stain when the chemical is mixed with sweat, urine, and/or feces, all of which are high in ammonia content. Dr. Crabbs also stated that although black discoloration of the animals' urine and feces had been noted during the study, it was unknown whether this condensation reaction could or would result in any type of histopathologic lesion. In response to whether additional glands had been affected, Dr. Crabbs specified that the degenerative lesion had been noted only in the sebaceous glands of the skin. Additionally, she stated that hair quality had not been affected. A final issue raised during the discussion was whether or not one could rule out the possibility that this lesion occurred secondary to follicular atrophy. Dr. Crabbs stated that, in this case, it was not possible to make that determination.

The third case was from a male high-dose $\mathrm{B} 6 \mathrm{C} 3 \mathrm{~F} 1$ mouse (Figures $4 \mathrm{E}$ and $4 \mathrm{~F}$ ). Histologically, the lesion was characterized by the presence of single or multiple variably sized, round, intracytoplasmic accumulations that often displaced and/or indented the nucleus. The accumulations exhibited varying tinctoral properties ranging from pale eosinophilic to amphophilic to pale basophilic. The following voting choices were provided: (1) intracytoplasmic inclusion bodies; (2) cytoplasmic invagination; (3) hyaline droplet accumulation; (4) intracytoplasmic accumulation; and (5) within normal limits. The preferred diagnosis of the PWG was that of intracytoplasmic accumulation. Although 39\% of the audience agreed with this choice, the voting was relatively split, and $37 \%$ chose intracytoplasmic inclusion bodies. Dr. Crabbs clarified that the lesion had been further evaluated via transmission electron microscopy (TEM). Since the term "inclusion bodies" is 
often associated with a viral infection, and TEM had definitively ruled out a viral etiology, "intracytoplasmic accumulation" was the most appropriate terminology in this instance.

Dr. Crabbs presented several TEM images of the accumulations and discussed some of the main features. Although TEM proved beneficial in further characterizing the nature of the accumulations, their exact composition was not determined. However, the accumulations exhibited features most consistent with that of protein. It was equivocal as to whether the accumulations were a product of the cell itself or material engulfed by the cell. The accumulations were variably enclosed within a membrane, suggesting this may have been accumulation within lysosomes. Whereas the accumulations were often adjacent to the nucleus, and frequently displaced it, they were never enclosed within the nuclear envelope, which thus confirmed their intracytoplasmic nature. Despite displacement of the nucleus, there were no overt signs of toxicologic change and/or damage to the nucleus or any cellular organelle.

The accumulations were present in both mice and rats and were noted not only in the skin, but also in the epithelium of the oral mucosa (mice and rats), forestomach (mice and rats), and esophagus (rats only). Additionally, in mice there were rare instances of intracytoplasmic accumulations in areas of squamous metaplasia in the larynx. Various histologic examples of these accumulations were presented to the audience. Additional tissues - including the rectum, biliary epithelium, periorbital tissue, kidney, and urinary bladder - were evaluated, but they did not depict the lesion.

The audience suggested that although there are no overt signs of active toxicologic damage, the accumulations might represent the aftermath of a previous toxicologic event. It was suggested that the skin's role in excretion should be taken into consideration when investigating the pathogenesis of this lesion. One audience member suggested that mass spectrometry could prove to be beneficial when further evaluating the composition of these accumulations. Finally, a few audience members stated that they felt they had previously seen this or a similar lesion in control rats. Dr. Crabbs stated that in this instance, the accumulations exhibited a dose-related increase in incidence and severity.

\section{New Rumors on Brain Tumors}

Dr. Holly Kolenda-Roberts (Experimental Pathology Laboratories, Inc., Research Triangle Park, NC, USA) presented three rat brain neoplasms from various carcinogenicity bioassays. These tumors were from a group of brain tumors from NTP and other sources that were identified to better characterize rat brain tumors with an immunohistochemistry panel. Study material included twenty-eight spontaneously occurring glial tumors (astrocytomas, oligodendrogliomas, gliomas), nine astrocytomas from treatment groups from a two-year drinking water study, and thirteen tumors from treatment groups from another chronic bioassay. Immunohistochemical stains included GFAP, Iba-1, RCA-1, OX-6, Olig2, and neurofilament (Table 1).

The first case was from a female rat from a control group that was a moribund sacrifice on day 656 . The neoplasm was a moderately well-demarcated tumor with small, uniformly sized cells with small round nuclei. In some cells, a small, perinuclear halo of clear cytoplasm could be seen (Figure 5A). In some areas, there were vessels that exhibited endothelial hyperplasia and hypertrophy ("vascular garlands"/"glomeruloid vascular proliferations"). A vote was taken in which the participants were given the following choices: (1) oligodendroglioma, (2) glioma, (3) astrocytoma, (4) malignant reticulosis, and (5) microglioma. Oligodendroglioma, the presenter's preferred choice, received $50 \%$ of the votes. The other votes recorded were astrocytoma (21\%), glioma (14\%), microglioma (8\%), and malignant reticulosis (7\%). 
After the voting was completed, representative images of the immunohistochemistry staining results were shown. These tumors were characterized by very strong and consistent staining of the neoplastic cells using the marker Olig2 (Figure 5B). There were scattered individual or clumps of cells that stained positively for RCA-1, Iba-1, OX-6, and GFAP. These tumors were negative for neurofilament. Of the twenty-eight spontaneous glial tumors, sixteen $(57 \%)$ were diagnosed as oligodendroglioma based on the immunohistochemistry results. Previous diagnoses for these sixteen oligodendrogliomas, based on histological appearance (H\&E) alone and before IHC confirmation, were oligodendroglioma (5), glioma/mixed glioma (6), astrocytoma (4), and gliosis (1).

The second case was from a male rat in a control group that was a moribund sacrifice on Day 700. The brain neoplasm diffusely infiltrated the parenchyma, and in some areas, neuronal satellitosis and perivascular cuffing by neoplastic cells could be observed (Figure 5C). Moderately sized neoplastic cells had indistinct cellular borders and round to elongated nuclei (Figure 5D). A vote was taken for the second tumor, and the participants were given the following choices: (1) oligodendroglioma, (2) glioma, (3) astrocytoma, (4) malignant reticulosis, and (5) microglioma. Microglioma, the speaker's preferred choice, received 22\% of the votes. The remaining votes were as follows: astrocytoma (47\%), malignant reticulosis (16\%), glioma (13\%), and oligodendroglioma (2\%).

Results of the immunohistochemical staining were presented. For tumors in this study that were identified as microgliomas, there was strong diffuse and consistent staining of the neoplastic cells with the markers for RCA-1 and Iba-1 (Figures 5E and 5F), whereas OX-6 (MHCII) was more variable and tended to be present in only a few scattered cells. With the stains for GFAP and Olig2, there were few admixed positive cells present within tumors. Staining for neurofilament was negative within populations of neoplastic cells. Of the twenty-eight spontaneous glial tumors in this study, nine (32\%) were found to be microgliomas. All of these neoplasms had been previously diagnosed as astrocytomas based on histological appearance alone. Thus, the voting results were to be expected; previously, based on the available morphologic criteria and information in the literature, pathologists would have diagnosed these tumors as astrocytomas. Rat "astrocytomas" were shown in our study to have a different cell of origin and were in fact microgliomas.

The third case was from a male rat from a high-dose group from a chronic bioassay that had an increased incidence of brain tumors in treated animals. Neoplastic cells exhibited infiltrative growth and extended onto the parenchymal surface (meninges) and around blood vessels (perivascular cuffing). Moderately sized neoplastic cells were round to elongate with variably distinct cellular borders (Figure $5 \mathrm{G}$ ). A vote was taken in which the participants were given the following choices: (1) oligodendroglioma, (2) glioma, (3) astrocytoma, (4) malignant reticulosis, and (5) microglioma. Microglioma, the speaker's choice, received 7\% of the votes. The remaining votes were as follows: astrocytoma (47\%), malignant reticulosis $(26 \%)$, glioma (19\%), and oligodendroglioma (1\%).

Thirteen animals in this bioassay had been previously diagnosed with gliomas. Based on the immunohistochemistry results, eight of these thirteen tumors were identified as microgliomas, two were oligodendrogliomas, one was a mixed tumor (oligodendroglial and microglial cells), and two exhibited insufficient staining. In these presumably chemically induced microgliomas, neoplastic cells had decreased staining intensity with RCA-1 and increased staining with OX-6 (MHCII; Figures 5H and 5I) when compared to the spontaneously occurring neoplasms. In addition, there were increased numbers of admixed GFAP+ and Olig2+ cells (10-30\%). 
For comparison, Dr. Kolenda-Roberts presented data from animals in the one 2-year drinking water study, which reported an increase in "astrocytomas" where all nine tumors exhibited staining consistent with microgliomas. The only observed difference between the chemically induced microgliomas from this study and spontaneous microgliomas was an increase in the subpopulations of GFAP+ and Olig2+ cells (10-30\%) in the chemically induced microgliomas.

The third case was included in this presentation to illustrate that, although oligodendrogliomas were the more commonly observed spontaneous rat brain neoplasm $(57 \%)$, microgliomas predominated in animals with chemically induced brain tumors. Chemically induced microgliomas differed slightly from spontaneous microgliomas, as there were mild increases in the numbers of admixed GFAP+ and Olig2+ cells. Also, chemically induced microgliomas from one chemical study showed changes in staining intensity for two of the microglial/macrophage markers, which may indicate a difference in cellular activation or protein expression for these neoplasms. In summary, immunohistochemistry was shown to provide valuable ancillary diagnostic information in the classification of rat brain tumors that was previously unavailable because of a lack of cellular markers.

\section{Microcytes Are Not Created Equal}

Dr. Travlos (NIEHS, NTP, Research Triangle Park, NC, USA) presented the next case involving review of a set of selected hematology data from the NTP subchronic toxicity study of sodium dichromate dihydrate (SDD). The data presented focused on the erythron and were from female rats sampled at day 23 and administered either 0 (control) or 1,000 $\mathrm{mg} / \mathrm{L}$ of SDD in the drinking water (Table 2). The audience was asked to characterize the erythron changes from the following choices: (1) normal; (2) anemia; (3) microcytic anemia; (4) microcytic, hypochromic anemia; (5) microcytic, hyperchromic anemia; (6) microcytic, hypochromic, responsive anemia; (7) microcytic, hyperchromic, responsive anemia; (8) microcytic, hypochromic, nonresponsive anemia; and (9) microcytic, hyperchromic, nonresponsive anemia. There was a mix of responses with no one response garnering more than $26 \%$ of the vote. In fact, two responses (i.e., choice 6, microcytic, hypochromic, responsive anemia; and choice 7 , microcytic, hyperchromic, responsive anemia) received equal numbers of votes to share the top spot at $26 \%$ of the poll.

What ensued was a discussion regarding the data and the apparent discrepancy between the directly determined packed cell volume (PCV) and the instrument-derived hematocrit (Hct) values reported for the 1,000 mg/L group (33.4\% and $19.5 \%$ for the PCV and Hct, respectively). Dr. Travlos presented additional information regarding the computation of the Hct by hematology instruments and the impact that erroneous Hct values can have on the calculation of the mean cell hemoglobin concentration results, which thus affects how erythron changes are characterized. Based on erythrocyte and platelet cytograms and/or histograms produced by the instrument used during this study (data not shown), Dr. Travlos discussed how it appeared the instrument misclassified small (microcytic), hypochromic erythrocytes as platelets, which resulted in erroneously low erythrocyte counts and Hct values and an overestimation of the mean cell volume, mean cell hemoglobin concentration, and platelet count results. Following the discussion, Dr. Travlos asked the group to reclassify the hematology data. This time, $44 \%$ selected the appropriate response, a microcytic, hypochromic, responsive anemia. Dr. Travlos then displayed photomicrographs of Romanowsky-stained blood films of the control and 1,000 mg/L groups taken using a $100 \times$, oil immersion objective to demonstrate the morphological differences (e.g., microcytes, schistocytes, hypochromia, polychromasia) between the groups. The morphology supported the diagnosis and reinforced the use of a blood smear review as an important tool that should be a component of a complete hematology evaluation. Because 
only the reticulocyte percentage was increased and not the absolute reticulocyte numbers, a small number of respondents (18\%) selected choice 8 , microcytic, hypochromic, nonresponsive anemia. Dr. Travlos suggested that since the instrument underestimated the erythrocyte count, it stood to reason that calculation of an artificially low absolute reticulocyte count would also occur. Thus, in this particular instance, the increased reticulocyte percentage was the more useful indicator of an erythropoietic response.

\section{Review of Microcytosis}

As a follow-up to the Travlos presentation, Dr. Kenneth S. Latimer (Covance Laboratories, Inc., Chantilly, VA, USA) presented a review of microcytes and microcytosis. Microcytosis may be caused by a number of acquired or hereditary conditions (Table 3), and the purpose of this review is to briefly discuss some of these conditions.

Iron deficiency is most commonly associated with chronic hemorrhage and external blood loss where iron is lost from the body and cannot be recycled for hemoglobin production (Figure 6A). Iron deficiency can also occur as a transient condition in young animals fed an all-milk diet. Microcytes (smaller erythrocytes with central pallor) are caused by decreased iron content that fails to arrest mitotic division of erythroid precursors, ultimately resulting in smaller progeny. Poikilocytes, such as keratocytes and schistocytes, may also occur from oxidation of erythrocytic membrane proteins (Brockus 2011; Weiss et al. 2010).

Pyridoxine (Vitamin $\left.\mathrm{B}_{6}\right)$ deficiency is another cause of microcyte formation. Since pyridoxine is a cofactor in heme synthesis, deficiency results in a failure to use iron for hemoglobin formation (Brockus 2011; Weiss et al. 2010).

Copper deficiency affects copper-associated proteins involved in iron transport, resulting in functional iron deficiency. Two major copper-associated proteins are hephaestin and ceruloplasmin, which act as copper-dependent ferroxidases. These enzymes change the valence of iron from the ferrous $\left(2^{+}\right)$to the ferric $\left(3^{+}\right)$state, facilitating its uptake and transport. Hephaestin is involved with the transfer of iron to ferroportin 1, promoting its transport from enterocytes to the plasma. Ceruloplasmin, associated with about $70 \%$ of copper content in the blood, is involved with iron transport from enterocytes and macrophages to all tissues of the body (Brockus 2011).

Pathologic production of erythrocyte remnants may occur in Heinz body anemia and microangiopathy. Heinz bodies are particulates that are attached to the inner red cell membrane and are composed of denatured hemoglobin following oxidative damage (Figure 6B). Free Heinz bodies may be released upon intravascular red cell destruction. Heinz bodies may also be pitted by macrophages, which results in spherocyte formation. In addition, oxidation, damage, and fragmentation of red cell membranes may promote the formation of eccentrocytes (hemighosts) and red cell ghosts with the release of free Heinz bodies. Microangiopathy is defined as damage to erythrocytes in the microvasculature that usually originates from fibrin strand deposition (e.g., disseminated intravascular coagulation) or turbulent blood flow (e.g., vascular channels in neoplasms or historically in early ball and sleeve heart valves), which results in poikilocyte formation (Brockus 2011; Weiss et al. 2010).

The presence of microcytes may also be a breed-specific finding in dogs of Asian descent such as the Akita, Chow Chow, Shar Pei, and Shiba Inu (Brockus 2011; Weiss et al. 2010). The decreased MCV is not associated with anemia. In cynomolgous monkeys (Macaca fasicularis), the source of the animals may be important as far as microcytosis is concerned (Hall and Everds 2003). The so-called "islanders" originating from Indonesia, Maritius, or the Philippines may have a lower MCV that varies from 58 to $68 \mathrm{fL}$. In contrast, the so- 
called "mainlanders" from China or Vietnam have a higher MCV ranging from $~ 70$ to 80 $\mathrm{fL}$. Because of these differences, cynomolgous monkeys for hematology study should have a uniform point of origin.

Hereditary dyserythropoiesis has also been described in English Springer Spaniels. In affected dogs, this condition is associated with the development of a microcytic, nonregenerative anemia (Brockus 2011).

Hereditary and acquired portosystemic shunts in dogs and, less frequently, in cats may be associated with microcytosis. Approximately one third of cats with portosystemic shunts may have demonstrable microcytosis (Brockus 2011). Other hematologic laboratory findings are similar to the anemia of chronic disease. Serum iron concentration and total iron binding capacity may be within the reference interval or decreased. Bone marrow and hepatic iron stores can be demonstrated with Perls' Prussian blue stain.

Therapeutic drugs may occasionally be associated with microcytosis. For example, chloramphenicol is a protein synthesis inhibitor that may block heme synthesis (Brockus 2011).

Lead toxicosis may be associated with the development of anemia at concentrations $>50 \mu \mathrm{g} /$ $\mathrm{dL}$. Anemia is often associated with hypochromia and metarubricytosis, but the demonstration of basophilic stippling with Romanowsky stains may be inconsistent. Lead toxicosis inhibits $\delta$-aminolevulinic acid dehydratase activity and blocks heme synthesis. Excess lead also inhibits ferrocheletase, which interferes with the combination of protophorphyrin and ferrous $\left(\mathrm{Fe}^{2+}\right)$ iron to form heme (Brockus 2011; Weiss et al. 2010).

Generalized poikilocytosis may also be detected as microcytosis by automated hematology analyzers (Figure 6C). Marked poikilocytosis may be a common finding in healthy goat kids, especially Angora goats (Weiss et al. 2010). Examples of compound-associated poikilocytosis have also been reported. Single-pulse dosing of rats with dimethylbenz(a)anthracene may produce a preleukemic myelodysplastic syndrome associated with anisocytosis, poikilocytosis, nuclear deformity, atypical mitoses, and megaloblastoid change (Fohlmeister et al. 1982). Furthermore, as discussed by Travlos, SDD administration to rats may also produce poikilocytosis and microcytosis (Bucher 2007). Uranyl nitrate administration to rats has been studied as a model of acute renal failure. Administration of this compound caused acute renal failure characterized by a hemolytic syndrome, anisocytosis, and poikilocytosis within twenty-four hours (Gojer and Sawant 1992).

Spherocytosis may be hereditary or acquired (Figure 6D). When biconcave erythrocytes (discocytes) are transformed to spherocytes by membrane removal, the MCV may be unchanged if cytoplasmic contents are not lost. If cytoplasmic content is removed, such as pitting of Heinz bodies, affected cells may have a decreased MCV. As far as hemoglobin content, spherocytes may be normochromic or hyperchromic.

Hereditary spherocytosis of mice has been studied in detail, and publications in the veterinary and comparative literature are relatively common (Robledo et al. 2010; Satchwell et al. 2009). This condition is frequently associated with cytoskeletal defects involving ankyrin, Band 3, Protein 4.2, or spectrin deficiency. For example, murine recessive hereditary spherocytosis is associated with the $\mathrm{sph} / \mathrm{sph}$ mutation in the C57BL/6J strain. Complete deficiency of band 3 has been characterized in inbred $\mathrm{CH} 3 / \mathrm{HeJ}$ mice. In contrast, early descriptions and publications of protein 4.2 deficiency failed to specifically identify the mouse strain. 
As previously discussed, acquired spherocytosis may be associated with immune-mediated hemolytic anemia and pitting of Heinz bodies. Antibody-mediated partial phagocytosis of erythrocytes by macrophages may result in decreased membrane surface area that encloses a normal amount of hemoglobin, resulting in a change from a biconcave to round erythrocyte. Round erythrocytes do not flatten well on blood smears. Following Romanowsky staining, spherocytes generally appear smaller and lack central pallor. From a research standpoint, acquired spherocytosis has been a consistent feature of some rat models of disease; however, the molecular basis of the change has not always been clearly defined. Vitamin $\mathrm{B}_{6}$-deficient and galactose-fed rats have erythrocyte changes characterized by spherocytosis, stomatocytosis, and "other" presentations of deformed erythrocytes (general poikilocytosis; Kaul et al. 1995). Administration of 2-butoxyethanol has also been associated with the production of spherocytes and stomatocytes (Ghanayem et al. 2000). Other causes of acquired spherocytosis in rats have included administration of methyl isocyanate and rabbit anti-rat erythrocyte serum, as well as estrogen-induced embolization of mesenteric arteries (Agrawal et al. 1990; Cooper 1972; Shimizu et al. 1987).

\section{The Funny Smell of Green Tea}

Dr. Abraham Nyska (Sackler School of Medicine, Tel Aviv University, Israel), in collaboration with Dr. Yuval Ramot (Hadassah-Hebrew University Medical Center, Jerusalem, Israel), presented nasal lesions in a F344/NTac male rat from an NTP fourteenweek study, in which green tea extract (GTE) had been given by gavage. Representative photomicrographs of histologic sections from control (Figure 7A) and treated (Figure 7B) rats were presented with the following diagnostic choices: (1) respiratory epithelium metaplasia, with presence of pigmented histiocytes; (2) transitional cell metaplasia, with presence of pigmented histiocytes; (3) olfactory epithelium atrophy with respiratory metaplasia, presence of pigmented histiocytes, and nerve fiber atrophy; and (4) all of the above diagnoses. The correct response (determined by pathology peer review), olfactory epithelium atrophy with respiratory metaplasia, presence of pigmented histiocytes, and nerve fiber atrophy, was the option favored by the audience (63\%).

Herbal supplements are frequently used in many countries, and their market has increased steadily over the past decade (Mohamed and Frye 2011). Among these products, green tea and Ginkgo biloba extracts are among the most widely used herbal supplements in Europe and the United States (Mohamed and Frye 2011). Green tea is reported to have many beneficial effects, such as antioxidative, anti-inflammatory, anticarcinogenic, thermogenic, probiotic, and antimicrobial properties (Graham 1992; Molinari et al. 2006). In the United States, the U.S. Food and Drug Administration has classified green tea as a generally regarded as safe (GRAS) compound (Wu and Wei 2002), and concentrated polyphenols are regulated as dietary supplements (Chow et al. 2003). Nevertheless, several adverse effects have been associated with its consumption. In humans, Exolise ${ }^{\circledR}$, a GTE product for weight reduction, has been associated with thirteen cases of elevated hepatocellular liver enzymes in France and Spain, which led to its market authorization suspension (Gloro et al. 2005; Sarma et al. 2008). Hepatic necrosis has also been reported in rodents, although the mechanism is not known (Chan et al. 2010).

Ginkgo biloba has been used in Chinese medicine for almost 3,000 years for treating heart and lung problems, and it is currently used as a popular dietary supplement to enhance memory. Its medical applications include improving brain function, strengthening the cerebrovascular and cardiovascular systems, neutralizing free radicals, stabilizing cellular energy production, and suppressing inflammation (Chan et al. 2007). Although it is widely used by the general population, limited information exists pertaining to the acute toxicity of Ginkgo biloba or its extracts in humans, and when reported, toxicity is usually attributed to 
drug interactions (Chan et al. 2007). Similarly, there is limited information on the acute toxicity of Ginkgo biloba in animals, although it was reported that Ginkgo biloba extract (GBE) did not produce organ damage or impairment of hepatic and renal functions in rodents in subchronic or chronic toxicity studies (Chan et al. 2007).

Because of the widespread use of green tea and Ginkgo biloba extracts, combined with the limited availability of toxicity studies performed with these compounds, the NTP has conducted fourteen-week toxicity studies with GTE administered by oral gavage to male and female F344/NTac rats (dosages up to $1,000 \mathrm{mg} / \mathrm{kg}$ ) and two-year toxicity studies with GBE administered by oral gavage to male and female F344 rats (dosages up to $1,000 \mathrm{mg} / \mathrm{kg}$ ). In both studies, similar treatment-related histopathological changes were observed in the nose, after examining the routinely collected three levels of nasal sections (Boorman et al. 1990). These changes included inflammation, olfactory epithelium atrophy, olfactory nerve atrophy, pigment accumulation in olfactory epithelium, and metaplasia of olfactory epithelium to respiratory epithelium. Additionally, respiratory epithelium hyperplasia and goblet cell hyperplasia were noted in the GBE study. No nasal carcinogenicity was seen in the nose in either study.

The pathogenesis by which administration of green tea and Ginkgo biloba extracts leads to nasal pathology is still obscure. One possible mechanism is by gastric reflux/post-gavage reflux through the nasopharyngeal duct. The predominant ventral and posterior distribution and the presence of nasopharyngeal duct lesions in many of the animals from the GBE study support this hypothesis. Typically, lesions induced by olfactory toxicants are most severe and primarily located in the more anterior sections of the nose and along the dorsal meatus, and they are generally not heavily suppurative (Renne et al. 2007). Additionally, material (hair or plant) was present in the inflammatory cell infiltrate in some of the nasopharyngeal ducts, further strengthening this theory.

Alternatively, the nasal lesions could be caused by exposure through the blood stream to the tested compound or its metabolites (Sells et al. 2007). In that regard, it is of note that in addition to the nose, the other major target tissue in both studies was the liver, two organs that are rich with metabolic activity. In fact, the CYP450 concentration in the rat olfactory epithelium is second only to the liver (Reed 1993). Furthermore, in both studies, the olfactory epithelium was more severely affected compared to the respiratory epithelium, which corresponds to the higher levels of enzymatic activity in the olfactory epithelium (Walsh and Courtney 1998).

It should be noted that no nasal carcinogenicity was seen in the nose with GTE and GBE following termination of the two-year studies, in both rats and mice. A relatively comparable range of lesions in the nose was seen in the three-month and two-year studies. In addition, no treatment-related effect was seen in any other segment of the respiratory tract, except for the nose, in any of the studies carried out by the NTP with GTE and GBE.

Nasal lesions are very common following inhalation studies; however, more than twenty different non-inhalation studies conducted by the NTP, using dermal, feed, drinking water or gavage route of administration, have shown nasal lesions, including neoplasms, making the nose a relatively common target organ (Sells et al. 2007). Nevertheless, the nose does not appear in the STP recommended tissue list for histopathological examination in oral route of administration studies (Bregman et al. 2003). Taken together, the accumulation of data on the susceptibility of the nose to toxic effects emphasizes the need for a thorough examination of the nasal passages regardless of the route of administration (Sells et al. 2007). 


\section{Corneal Dystrophy in Dutch Belted Rabbits}

Dr. JoAnn Schuh (JCL Schuh, PLLC, Bainbridge Island, WA, USA) presented a case series entitled "2011, Year of the Rabbit Eyes" that was contributed in conjunction with Dr. Dana Holve and Karen Mundwiler (Biological Test Center, Irvine, CA, USA). This presentation described a four-month research study of fifteen young (5.5 months old) male Dutch belted rabbits (Oryctolagus cuniculus) with spontaneous corneal opacities. Examples of the lesions imaged by slit-lamp biomicroscopy and optical coherence tomography (OCT) were followed by presentation of photomicrographs of the corneal lesion with Masson's trichrome, H\&E, hematoxylin, phloxine and saffron, periodic acid-Schiff, and congo red stains (data not shown). The voting choice results were corneal dysplasia (16\%), corneal fibrosis (35\%), corneal lipidosis $(6 \%)$, corneal dystrophy (39\%), corneal amyloidosis (4\%), and other (0\%).

Comparative images of a normal and an affected cornea (Figure 8) were used to show that these discrete lesions were characterized by changes to epithelium (thinning over the lesion and thickening at the edges) and subjacent superficial stroma (increased number and size of keratinocytes in enlarged spaces and disarray and enhanced tinctorial staining of irregular stromal fibers). Dr. Schuh discussed how the young age, source from a single production facility, clinical history, and characteristics of the histopathology and histochemistry allow all but corneal dysplasia or dystrophy to be eliminated from the diagnostic choices. Dr. Schuh defined and characterized dystrophy (Dys, wrong or difficult +trophe, nourishment; a noninflammatory nutritional or metabolic disorder generally resulting from a genetic defect and abnormal proteins and most frequently in muscle and ocular tissues) versus dysplasia (Dys + plassein, to form; any abnormal growth or growth pattern of tissues or organ). Based on this information, these rabbits were diagnosed with superficial corneal dystrophy (Moore et al. 1987).

It was emphasized that the diagnosis of corneal dystrophy has been imprecisely applied to a variety of ocular abnormalities in animals. In humans, true corneal dystrophy is a heterogenous group of genetically determined noninflammatory diseases defined by phenotype, genotype, and pathologic examination (Weiss et al. 2008). It was concluded that the rabbits in this study have a true corneal dystrophy that may be comparable to ThielBehnke corneal dystrophy (TBCD). Transmission electron microscopy is required to differentiate TBCD from Reis-Bücklers corneal dystrophy (RBCD), as both are variant defects in transforming growth factor- $\beta 1$ expression. A preliminary electron micrograph from one of the rabbit corneas was presented showing the curly fibers in the stromal component that may be consistent with TBCD as opposed to the rod-shaped bodies expected in RBCD (data not shown). The OCT imaging used in this study was a valuable technique for providing high-resolution imaging that was predictive of the histological localization and allowed in vivo evaluation of the progression of the lesions.

\section{What's in a Name: Valvulopathy or Valvular Endocarditis or Other?}

Dr. Ricardo Ochoa (Pre-Clinical Safety Inc., Niantic, CT, USA) presented a case characterized by thickening of the mitral valve in rats during a two-week toxicology study with an undisclosed compound that stimulated erythrocyte production. Studies were performed in nonhuman primates and in rats, but the lesions observed were found only in treated rats. Similar lesions were not present in control animals. In three replicates, six of six, one of six, and four of six rats had a similar change in the heart and extramedullary hematopoiesis was observed in zero of six controls and six of six, five of six, and six of six of the three replicates. Reticulocyte counts were very high in all high-dose animals, and hematocrit levels in affected rats were on the order of 60-70\%. After reviewing a series of images (Figures 9A-9D), the audience was asked to vote and the results of the voting were: 
valvulitis and thrombosis (59\%), valvulopathy (27\%), valvular thrombosis (6\%), endocarditis (3\%), cardiomyopathy $(0 \%)$, and other $(6 \%)$. The diagnosis of the study pathologist was valvulitis with thrombosis.

Normal valves were characterized by a thin structure containing the three characteristic layers of fibrosa, spongiosa, and ventricularis (Figure 9A). Valves in the affected animals were thickened by a proliferation of the endothelial surface, primarily on the ventricularis side of the valve (Figures 9B and 9C). The proliferating cells were endothelial, and some polymorphonuclear cells were also present. As seen in Figures 9B and 9C, a thrombus is attached on the ventricularis surface, justifying the diagnosis of valvulitis with thrombosis. Noticeably, the spongiosa layer is not thickened. When the audience was asked to vote for an assessment of whether this change was a direct effect of the compound, a spontaneous change, an expression of septicemia, or a consequence of hyperviscosity, the majority felt that this would be a direct effect of the compound.

It is necessary in these situations to differentiate "valvulitis" (valvular endocarditis, valvular inflammation) from the term "valvulopathy." The principal comparative diagnosis is valvulopathy. This term has been used recently to designate the condition of valvular thickening that resulted in cardiac insufficiency and mortality as a result of consumption of fenfluramines and pergolide, which activate the 5HT2b receptor (Elangbam 2010). These valvular changes resembled lesions observed in carcinoid disease (carcinoid tumors of the gastrointestinal tract that have metastasized to the liver) and lesions observed after exposure to ergotamines (Elangbam 2010). The compound used in the reported study was tested for $5 \mathrm{HT} 2 \mathrm{~b}$ activity, and the results were negative.

5HT2b activation induces proliferation in vitro with valvular interstitial cells of the spongiosa layer and increasing the production of glucosaminoglycans in the valve (Figures $3 \mathrm{~A}$ and 3B; Elangbam 2010). This case illustrates the type of proliferation that is to be expected in the activation of 5HT2b. It is important to note that the valvulopathy that affects humans is difficult to reproduce in animals, and the illustration presented by Elangham demonstrates a case more consistent with the diagnosis of valvulopathy in the rat. The valvulitis presented at this symposium is more consistent with the effects observed in severe hemoconcentration resulting from increases in erythrocyte counts or the presence of excessive globulinemia, as in Waldenstrom macroglobulinemia and multiple myeloma. This condition is referred to as "hyperviscosity syndrome" (http://emedicine.medscape.com/ article/780258-overview). Hyperviscosity is considered a risk factor for valvular endocarditis. As hyperviscosity occurs with high mountain disease, where erythropoiesis is increased to levels that can become dangerous, valvular endocarditis can ensue. An experimental approach to the clarification of this mechanism was published in 1955, where endocarditis was induced by a combination of hypoxia, cobalt and E. coli exposure (Highman and Altland 1955).

Therefore, the final evaluation of this change is that it is secondary to the polycythemia observed in these animals that resulted in hyperviscosity. Even in high mountain disease, it is difficult to observe such a high polycythemia as was induced in these animals as a consequence of the contrived experimental model that exposed these animals to very high doses. Clinically, human subjects will not have a comparable risk, as these high hematocrit values would not be attained in the course of therapeutic use of these drugs.

During subsequent discussion, an audience member asked if one would expect peripheral lesions with hyperviscosity syndrome. In the present case, peripheral lesions, such as thrombi, were not observed in any organ, perhaps because treatment was not long enough to allow development of secondary lesions. Also, there was no indication of cardiac dilatation 
nor pulmonary edema, although these effects would be expected with time. The only systemic observation was that the regular bleeding of the carcass after sacrifice in the study was slow, and most organs had more retained blood within capillaries when compared to controls. This result was interpreted as related to sluggish blood flow, not allowing for complete exsanguination. Dr. Ochoa indicated that the term "hyperemia" was chosen for this finding, in order to avoid "congestion," which would have more of a connotation of organ inflammatory changes or passive accumulation of blood. Also, no viscosity measurements were taken from the blood in this case.

Another question related to whether the mechanisms for the high altitude model report may have been related to septicemia. Dr. Ochoa responded that the model described uses bacteria to mimic what normally happens in individuals. On a regular basis, bacteria and toxins gain access to circulation from the intestine. These organisms may lodge in locations that suit their environmental needs, increasing the probability of valvular endocarditis under certain conditions. One audience member's comment concerned the use of "valvulopathy" as a noncommittal term. Dr. Ochoa responded that the term valvulopathy has now become such a specialized term that it is better to use other terms that do not invoke the specific 5HT2b mechanism, unless one is sure that this is a likely possibility.

Finally, one attendant questioned whether, with the present trend to use more descriptive diagnostic terms, "valvular thickening" should be a better choice. Dr. Ochoa indicated that the diagnostic term should represent as much information as possible from the pathologist. "Thickening" would be too vague, as there was more information present in the lesion, and this extra information should be represented in the diagnosis. Using just "thickening" will force the pathologist to create additional diagnoses (such as neutrophilic infiltration, endocardial proliferation), which would create confusion. Terms should clarify the diagnosis and be as concise and comprehensive as possible.

\section{Post-Transplant Lymphoproliferative Disease in a Monkey}

Dr. Jerrold M. Ward (Global VetPathology and NIAID, NIH, MD, USA), in collaboration with Andrew D. Miller (Harvard Medical School, Southborough, MA, USA), presented a case of lymphoid lesions in a monkey. The case was from the files of Drs. Andrew Miller and Keith Mansfield of The New England Primate Research Center (Carville and Mansfield 2008). An eight-year-old male cynomolgus monkey (crab-eating macaque; $M$. fascicularis) had a bilateral renal harvest and a unilateral kidney transplant after preventive antibiotics and immunosuppressive medication (thymoglobulin and rapamycin). The monkey did well until thirty days later, when there was an increase in serum creatinine. Its condition deteriorated over the next nine days, and the monkey was euthanized. At necropsy, a copious amount of pleural and peritoneal fluid was found, along with splenomegaly, and enlarged peripheral lymph nodes and liver.

After reviewing a series of images (Figures 10A-10C), the audience was asked to vote. The results of the voting were: lymphoid hyperplasia (2\%), lymphocytic lymphoma (29\%), plasma cell lymphoma (15\%), follicular (mixed cell type) lymphoma (28\%), myeloproliferative disease (6\%), and lymphoproliferative disease (19\%). The diagnosis of the study pathologist was lymphoproliferative disease.

Histologically, there was marked infiltration of immature lymphoid cells in the kidney, liver (Figure 10A), and adrenals. In the spleen, similar cells expanded the white pulp and lymph node architecture was effaced by these infiltrating lymphoid cells. The lymphoid cell population was composed of many lymphoblasts with large nucleoli, medium-sized lymphocytes, mature lymphocytes, and plasmacytoid cells including plasmablasts, immunoblasts, and plasma cells (Figures 10B and 10C). The populations of lymphoid cells 
in any specific microscope field varied from predominantly blasts (Figure 10C) to a mixed population of all cell types. The cells massively infiltrated the adrenals and liver, a process resembling a lymphoma infiltrate. Immunohistochemistry revealed that most infiltrating lymphocytes were CD20+ (Figure 11D) and CD3- and expressed Epstein-Barr nuclear antigen (Figure 11E) and BZLF1 (a herpes viral lytic antigen). Many CD3+ lymphocytes were also found in the liver infiltrates. Occasional CMV intranuclear inclusion bodies were found in endothelial cells of renal veins (Figure 11F) and other tissues.

This case represents the nonhuman primate equivalent of the human post-transplant lymphoproliferative disease (PTLD), polymorphic form (Swerdlow et al. 2008). Monkey cases have been reported in only two publications (Carville and Mansfield 2008; Schmidtko et al. 2002) and appear to represent a syndrome in monkeys in post-transplant immunosuppressive situations. In one large study of 160 renal transplants in monkeys over a five-year period, nine developed PTLD. Polymorphic PTLD has a greater chance of natural regression in humans and probably in monkeys, whereas the monomorphic PTLD is basically a B-cell neoplasm. Since no clonality assays were done for this case, and the morphology is polymorphic, the authors assume it is a case of polymorphic PTLD. A medical pathologist expert in human lymphoma confirmed this monkey diagnosis.

Investigators developing immunosuppressive therapies and/or testing immunosuppressive compounds in monkeys should be aware of the possibility of the development of herpesvirus-induced PTLD. One could easily mistake this situation for the induction of lymphoma by the test compound. The PTLD usually occurs thirty to one hundred days posttransplantation.

\section{Acknowledgments}

The authors wish to thank Eli Ney of the NIEHS for her unique and creative cover artwork for the Symposium handouts as well as for her technical expertise in formatting the speaker's PowerPoint presentations. Thanks also to both Eli Ney and Beth Mahler of EPL for their assistance with manuscript image preparation and to David Sabio of EPL for assistance during the Symposium. Appreciation also goes to Sue Pitsch, Krystle Correll, Tierre Miller, and Maureen Kettering of Association Innovation and Management, Inc. for their valuable help with annual advertising and meeting facilities. Also integral to the success of this meeting was the security provided by William Stoeffler of the Stoeffler Group, LLC. This research was supported (in part) by the Intramural Research Program of the National Institutes of Health (NIH), National Institute of Environmental Health Sciences (NIEHS). This article may be the work product of an employee or group of employees of the NIEHS, NIH; however, the statements, opinions or conclusions contained therein do not necessarily represent the statements, opinions or conclusions of NIEHS, $\mathrm{NIH}$, or the United States government.

The authors received no financial support for the research and/or authorship of this article.

\section{Abbreviations}

BZLF1

EBNA-2

fL

GBE

GFAP

GRAS

GTE

Het
Epstein-Barr Virus Immediate-Early Protein

Epstein-Barr nuclear antigen

femtoliter

Ginkgo biloba extract

glial fibrillary acidic protein

generally recognized as safe

green tea extract

hematocrit 


$\begin{array}{ll}\text { HSD } & \text { Harlan Sprague Dawley } \\ \text { Iba-1 } & \text { ionized calcium-binding adapter molecule-1 } \\ \text { MCV } & \text { mean corpuscular volume } \\ \text { MRC OX-6 } & \text { MHC class II antibody } \\ \text { NSE } & \text { neuron specific enolase } \\ \text { NTP } & \text { National Toxicology Program } \\ \text { OCT } & \text { optical coherence tomography } \\ \text { Oligo2 } & \text { oligodendrocyte transcription factor 2 } \\ \text { OPA } & \text { o-phthalaldehyde } \\ \text { PCV } & \text { packed cell volume } \\ \text { PGP 9.5 } & \text { protein gene product 9.5 } \\ \text { PTLD } & \text { post-transplant lymphoproliferative disease } \\ \text { PWG } & \text { pathology working group } \\ \text { RCA-1 } & \text { lectin Ricinus communis agglutinin type 1 } \\ \text { SDD } & \text { sodium dichromate dihydrate } \\ \text { STP } & \text { Society of Toxicologic Pathology } \\ \text { TEM } & \text { transmission electron microscopy }\end{array}$

\section{References}

Adams ET, Auerbach S, Blackshear PE, Bradley A, Gruebbel MM, Little PB, Malarkey D, Maronpot R, McKay JS, Miller RA, Moore RR, Morrison JP, Nyska A, Ramot Y, Rao D, Suttie A, Wells MY, Willson GA, Elmore SA. Proceedings of the 2010 National Toxicology Program Satellite Symposium. Toxicol Pathol. 2011; 39:240-266. [PubMed: 21177527]

Agrawal D, Gupta GS, Shukla JS, Dutta KK, Ray PK. Effect of methyl isocyanate (MIC) on rat erythrocytes. Arch Toxicol. 1990; 64:332-335. [PubMed: 2143649]

Anderson BC, Cordy DR. Olfactory neuroblastoma in a heifer. Vet Pathol. 1981; 18:536-540. [PubMed: 7257093]

Bach U, Hailey JR, Hill GD, Kaufmann W, Latimer KS, Malarkey DE, Maronpot RM, Miller RA, Moore RR, Morrison JP, Nolte T, Rinke M, Rittinghausen S, Suttie AW, Travlos GS, Vahle JL, Willson GA, Elmore SA. Proceedings of the 2009 National Toxicology Program Satellite Symposium. Toxicol Pathol. 2010; 38:9-36. [PubMed: 20008954]

Boorman, GA.; Morgan, KT.; Uriah, LC. Nose, larynx, and trachea. In: Boorman, GA.; Eustis, SL.; Elwell, MR.; Montgomery, CA.; MacKenzie, WF., editors. Pathology of the Fischer Rat, Reference and Atlas. San Diego, CA: Academic Press; 1990. p. 316-317.

Bregman CL, Adler RR, Morton DG, Regan KS, Yano BL. Recommended tissue list for histopathologic examination in repeat-dose toxicity and carcinogenicity studies: A proposal of the Society of Toxicologic Pathology (STP). Toxicol Pathol. 2003; 31:252-253. [PubMed: 12696587]

Brockus, CW. Erythrocytes. In: Latimer, KS., editor. Duncan \& Prasse's Veterinary Laboratory Medicine: Clinical Pathology. 5th ed.. Ames, IA: Wiley-Blackwell; 2011. p. 3-44.

Bucher J. NTP Toxicity Studies of Sodium Dichromate Dihydrate (CAS No. 7789-12-0) Administered in Drinking Water to Male and Female F344/N Rats and B6C3F1 Mice and Male BALB/c and am3C57BL/6 Mice. Toxic Rep Ser. 2007:1-G4. [PubMed: 17342194]

Carville A, Mansfield K. Comparative pathobiology of macaque lymphocryptoviruses. Comp Med. 2008; 58:57-67. [PubMed: 19793458] 
Chan PC, Ramot Y, Malarkey DE, Blackshear P, Kissling GE, Travlos G, Nyska A. Fourteen-week toxicity study of green tea extract in rats and mice. Toxicol Pathol. 2010; 38:1070-1084. [PubMed: 20884815]

Chan PC, Xia Q, Fu PP. Ginkgo biloba leave extract: Biological, medicinal, and toxicological effects. J Environ Sci Health C Environ Carcinog Ecotoxicol Rev. 2007; 25:211-244. [PubMed: 17763047]

Chow HH, Cai Y, Hakim IA, Crowell JA, Shahi F, Brooks CA, Dorr RT, Hara Y, Alberts DS. Pharmacokinetics and safety of green tea polyphenols after multiple-dose administration of epigallocatechin gallate and polyphenon E in healthy individuals. Clin Cancer Res. 2003; 9:33123319. [PubMed: 12960117]

Cooper RA. Loss of membrane components in the pathogenesis of antibody-induced spherocytosis. J Clin Invest. 1972; 51:16-21. [PubMed: 5007048]

Correa P, Dalgard DW, Adamson RH. Olfactory neuroepithelioma in a cynomolgus monkey (Macaca fascicularis). J Med Primatol. 1975; 4:51-61. [PubMed: 1123841]

Cox NR, Powers RD. Olfactory neuroblastomas in two cats. Vet Pathol. 1989; 26:341-343. [PubMed: 2763423]

Elangbam CS. Drug-induced valvulopathy: An update. Toxicol Pathol. 2010; 38:837-848. [PubMed: 20716786]

Faragalla H, Weinreb I. Olfactory neuroblastoma: A review and update. Adv Anat Pathol. 2009; 16:322-331. [PubMed: 19700942]

Fohlmeister I, Schaefer HE, Fischer R. On the pathogenesis of preleukemic myelodysplastic syndromes: Development of a dysplastic hemopoietic proliferation in the rat after a single pulse dose of dimethylbenz(a)anthracene (DMBA). J Cancer Res Clin Oncol. 1982; 104:249-261. [PubMed: 6819300]

Fournie JW, Hawkins WE, Walker WW. Proliferative lesions in swim bladder of Japanese medaka Oryzias latipes and guppy Poecilia reticulata. Dis Aquat Org. 1999; 38:135-142. [PubMed: 10598284]

Garcia H, Keefer L, Lijinsky W, Wenyon CE. Carcinogenicity of nitrosothiomorpholine and 1nitrosopiperazine in rats. Z Krebsforsch. 1970; 74:179-184. [PubMed: 4252983]

Ghanayem BI, Ward SM, Chanas B, Nyska A. Comparison of the acute hematotoxicity of 2butoxyethanol in male and female F344 rats. Hum Exp Toxicol. 2000; 19:185-192. [PubMed: 10889517]

Gloro R, Hourmand-Ollivier I, Mosquet B, Mosquet L, Rousselot P, Salame E, Piquet MA, Dao T. Fulminant hepatitis during self-medication with hydroalcoholic extract of green tea. Eur J Gastroenterol Hepatol. 2005; 17:1135-1137. [PubMed: 16148563]

Gojer M, Sawant V. Uranyl nitrate induced corpuscular derangement: An early indication of induced acute renal failure. Indian J Exp Biol. 1992; 30:119-121. [PubMed: 1521860]

Graham HN. Green tea composition, consumption, and polyphenol chemistry. Prev Med. 1992; 21:334-350. [PubMed: 1614995]

Grim KC, Wolfe MJ, Edwards M, Kaufman J, Onjukka S, Moran P, Wolf JC. Epizootic ameloblastomas in Chinook salmon (Oncorhynchus tshawytscha) of the northwestern United States. Vet Pathol. 2009; 4:622-635. [PubMed: 19276053]

Hall RL, Everds NE. Factors affecting the interpretation of canine and nonhuman primate clinical pathology. Toxicol Pathol. 2003; 31(Suppl):6-10. [PubMed: 12597425]

Haynes JS, Leininger JR. Malignant neuroblastoma in a cow. Vet Pathol. 1984; 21:610-612. [PubMed: 6516182]

Highman B, Altland P. Effect of altitude and cobalt polycythemia, hypoxia, and cortisone on susceptibility of rats to endocarditis. Circul Res. 1955; 3:351-356.

Kaul P, Sidhu H, Thind SK, Sharma SK, Nath R. Vitamin B6 deficiency and galactose induced alterations in morphology and osmotic fragility of rat erythrocytes. Scanning Microsc. 1995; 9:1127-1135. discussion 1135-36. [PubMed: 8819894]

Long PH, Herbert RA, Peckham JC, Grumbein SL, Shackelford CC, Abdo K. Morphology of nasal lesions in F344/N rats following chronic inhalation exposure to naphthalene vapors. Toxicol Pathol. 2003; 31:655-664. [PubMed: 14585734] 
Love LA, Lijinsky W, Keefer LK, Garcia H. Chronic oral administration of 1-nitrosopiperazine at high doses to MRC rats. Z Krebsforsch Klin Onkol Cancer Res Clin Oncol. 1977; 89:69-73. [PubMed: 141802]

Lund VJ, Howard D, Wei W, Spittle M. Olfactory neuroblastoma: Past, present, and future? Laryngoscope. 2003; 113:502-507. [PubMed: 12616204]

Mattix ME, Mattix RJ, Williams BH, Ribas JL, Wilhelmsen CL. Olfactory ganglioneuroblastoma in a dog: A light, ultrastructural, and immunohistochemical study. Vet Pathol. 1994; 31:262-265. [PubMed: 8203095]

Mohamed ME, Frye RF. Effects of herbal supplements on drug glucuronidation. Review of clinical, animal, and in vitro studies. Planta Med. 2011; 77:311-321. [PubMed: 21049395]

Molinari M, Watt KD, Kruszyna T, Nelson R, Walsh M, Huang WY, Nashan B, Peltekian K. Acute liver failure induced by green tea extracts: Case report and review of the literature. Liver Transpl. 2006; 12:1892-1895. [PubMed: 17133573]

Moore CP, Dubielzig R, Glaza SM. Anterior corneal dystrophy of American Dutch belted rabbits: Biomicroscopic and histopathologic findings. Vet Pathol. 1987; 24:28-33. [PubMed: 3493580]

Pelfrene A, Garcia H. Chemically induced esthesioneuroblastomas in rats. Z Krebsforsch Klin Onkol Cancer Res Clin Oncol. 1976; 86:113-119. [PubMed: 132783]

Reed CJ. Drug metabolism in the nasal cavity: Relevance to toxicology. Drug Metab Rev. 1993; 25:173-205. [PubMed: 8449146]

Renne RA, Gideon KM, Harbo SJ, Staska LM, Grumbein SL. Upper respiratory tract lesions in inhalation toxicology. Toxicol Pathol. 2007; 35:163-169. [PubMed: 17325985]

Robledo RF, Lambert AJ, Birkenmeier CS, Cirlan MV, Cirlan AF, Campagna DR, Lux SE, Peters LL. Analysis of novel sph (spherocytosis) alleles in mice reveals allele-specific loss of band 3 and adducin in alpha-spectrin-deficient red cells. Blood. 2010; 115:1804-1814. [PubMed: 20056793]

Sarma DN, Barrett ML, Chavez ML, Gardiner P, Ko R, Mahady GB, Marles RJ, Pellicore LS, Giancaspro GI, Low Dog T. Safety of green tea extracts: a systematic review by the US Pharmacopeia. Drug Saf. 2008; 31:469-484. [PubMed: 18484782]

Satchwell TJ, Shoemark DK, Sessions RB, Toye AM. Protein 4.2: A complex linker. Blood Cells Mol Dis. 2009; 42:201-210. [PubMed: 19269200]

Schmidtko J, Wang R, Wu CL, Mauiyyedi S, Harris NL, Della Pelle P, Brousaides N, Zagachin L, Ferry JA, Wang F, Kawai T, Sachs DH, Cosimi BA, Colvin RB. Posttransplant lymphoproliferative disorder associated with an Epstein-Barr-related virus in cynomolgus monkeys. Transplantation. 2002; 73:1431-1439. [PubMed: 12023621]

Sells DM, Brix AE, Nyska A, Jokinen MP, Orzech DP, Walker NJ. Respiratory tract lesions in noninhalation studies. Toxicol Pathol. 2007; 35:170-177. [PubMed: 17325986]

Shimizu Y, Nagamine Y, Fujiwara S, Suzuki J. An experimental study of chemical embolization using conjugated estrogen-ultrastructural observations on rat mesenteric vessels [article in Japanese]. No Shinkei Geka. 1987; 15:513-521. [PubMed: 2819757]

Swerdlow, SH.; Webber, SA.; Chadburn, A.; Ferry, JA. Post-transplant lymphoproliferative disorders. In: Swerdlow, SH.; Campos, E.; Harris, NL.; Jaffe, ES.; Pileri, SA.; Stein, H.; Thiele, J.; Vardiman, JW., editors. WHO Classification of Tumours of Haematopoietic and Lymphoid Tissues. Lyon, France: IARC Scientific Publications; 2008. p. 343-349.

Vidal-Dorsch D, Bay S, Mays M, Greenstein D, Young D, Wolf JC, Pham D, Loguinov A, Vulpe C. Using gene expression to assess the status of fish from anthropogenically influenced estuarine wetlands. Environ Sci Technol. 2011 Aug 17. 2011 [Epub ahead of print].

Walsh KM, Courtney CL. Nasal toxicity of CI-959, a novel anti-inflammatory drug, in Wistar rats and Beagle dogs. Toxicol Pathol. 1998; 26:717-723. [PubMed: 9864087]

Weiss, DJ.; Wardrop, KJ. Schalm's Veterinary Hematology. 6th ed.. Ames, IA: Wiley-Blackwell; 2010. p. 101p. 144-146.p. 167p. 170

Weiss JS, Møller HU, Lisch W, Kinoshita S, Aldave AJ, Belin MW, Kivelä T, Busin M, Munier FL, Seitz B, Sutphin J, Bredrup C, Mannis MJ, Rapuano CJ, VanRij G, Kim EK, Klintworth GK. The IC3D classification of the corneal dystrophies. Cornea. 2008; 27(Suppl 2):S1-S42. [PubMed: 19337156] 
Wolf JC, Wolfe MJ. A brief overview of nonneoplastic hepatic toxicity in fish. Toxicol Pathol. 2005; 33:75-85. [PubMed: 15805058]

Wu CD, Wei GX. Tea as a functional food for oral health. Nutrition. 2002; 18:443-444. [PubMed: 11985958]

Yamate J, Izawa T, Ogata K, Kobayashi O, Okajima R, Kuwamura M, Kotani T, Aoki M. Olfactory neuroblastoma in a horse. J Vet Med Sci. 2006; 68:495-498. [PubMed: 16757894] 

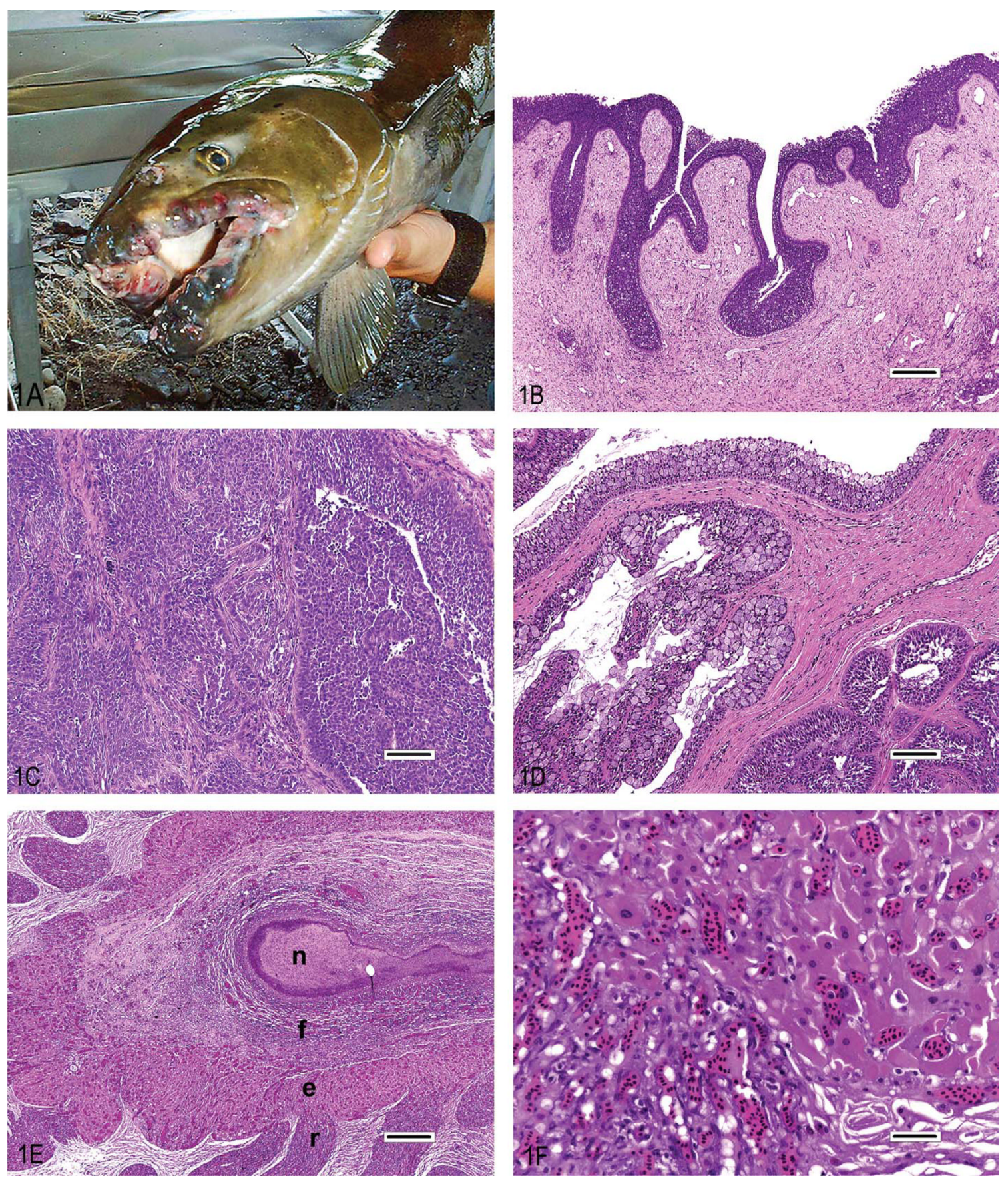

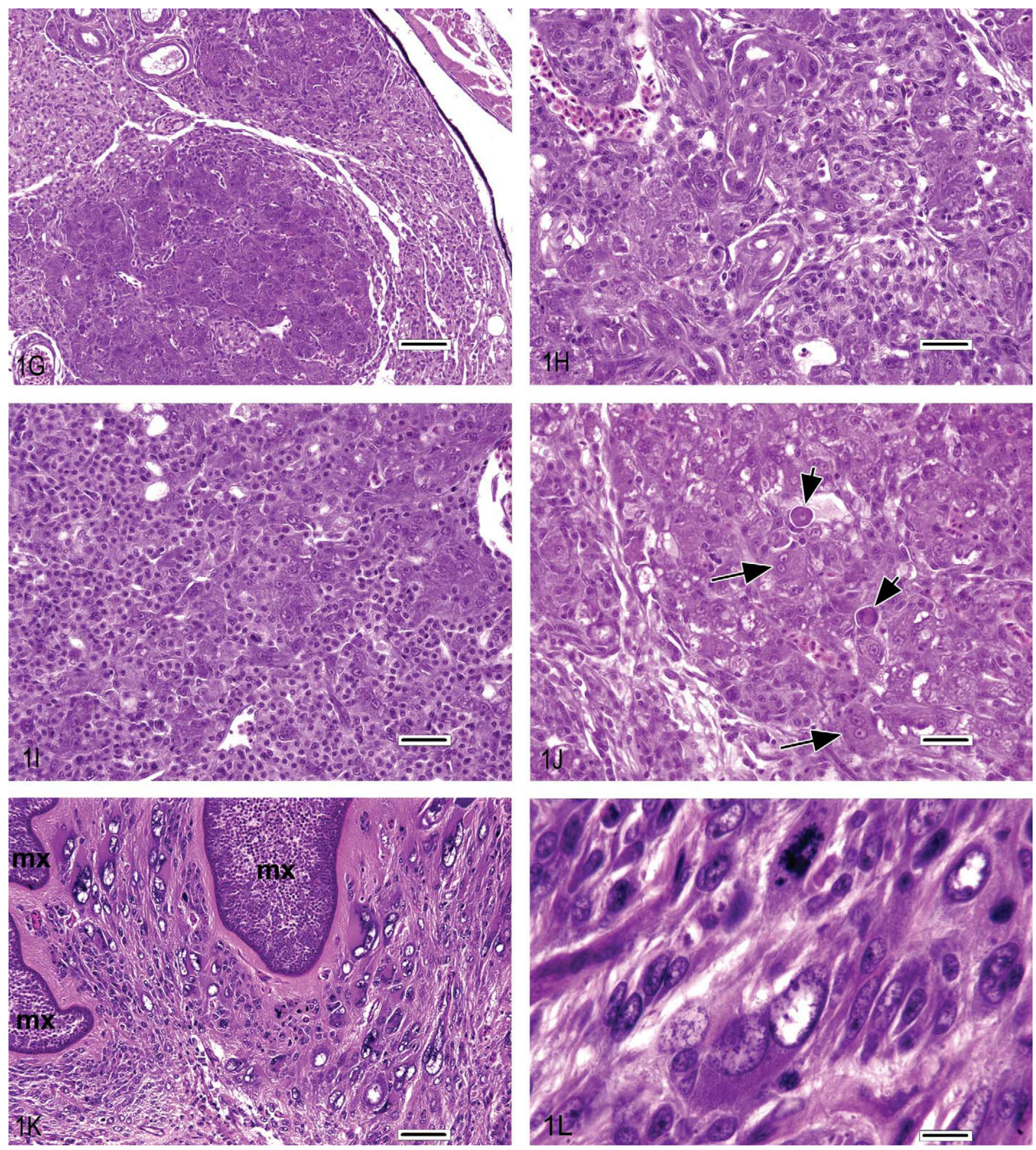

Figure 1. Various proliferative lesions that have been diagnosed in different fish species (A) Gross photo of Chinook salmon with oral ameloblastomas. (B) Early hyperplastic lesions extend deep from clefts in the oral mucosal surface. (C) Advanced ameloblastoma with characteristic crevices. (D) Occasional ameloblastomas displayed mucous cell differentiation. (E) Swim bladder gas gland hyperplasia in an Atlantic spadefish. A core of inflammatory cells and necrotic material (n) is surrounded in turn by zones of fibrovascular proliferation (f, likely remnant of the swim bladder wall), hyperplastic gas gland epithelial tissue (e), and hyperplastic vascular rete tissue (r). (F) High-magnification view of junction between the hyperplastic gas gland epithelium and vascular rete tissue. (G) Chemically induced nodular regenerative hepatocellular hyperplasia in a Japanese medaka. (H) High 
magnification of liver to illustrate primitive bile duct formation and a few clusters of regenerating hepatocytes. (I) Hepatic oval cell proliferation. (J) Individual cell apoptotic necrosis (short arrows) and binucleate hepatocytes (long arrows). (K) Malignant granulosa cell tumor in a longjaw mudsucker. Microsporidian xenomas $(\mathrm{mx})$ are surrounded by neoplastic granulosa cells with massively enlarged and bizarre nuclei. (L) Highmagnification view of neoplastic cells and aberrant mitotic figure. All histology images are hematoxylin and eosin-stained sections. Bar sizes $(\mu \mathrm{m}): \mathrm{B}=250, \mathrm{C}=100, \mathrm{D}=100, \mathrm{E}=$ $250, \mathrm{~F}=25 . \mathrm{G}=50, \mathrm{H}=25, \mathrm{I}=25, \mathrm{~J}=25, \mathrm{~K}=50, \mathrm{~L}=10$. 

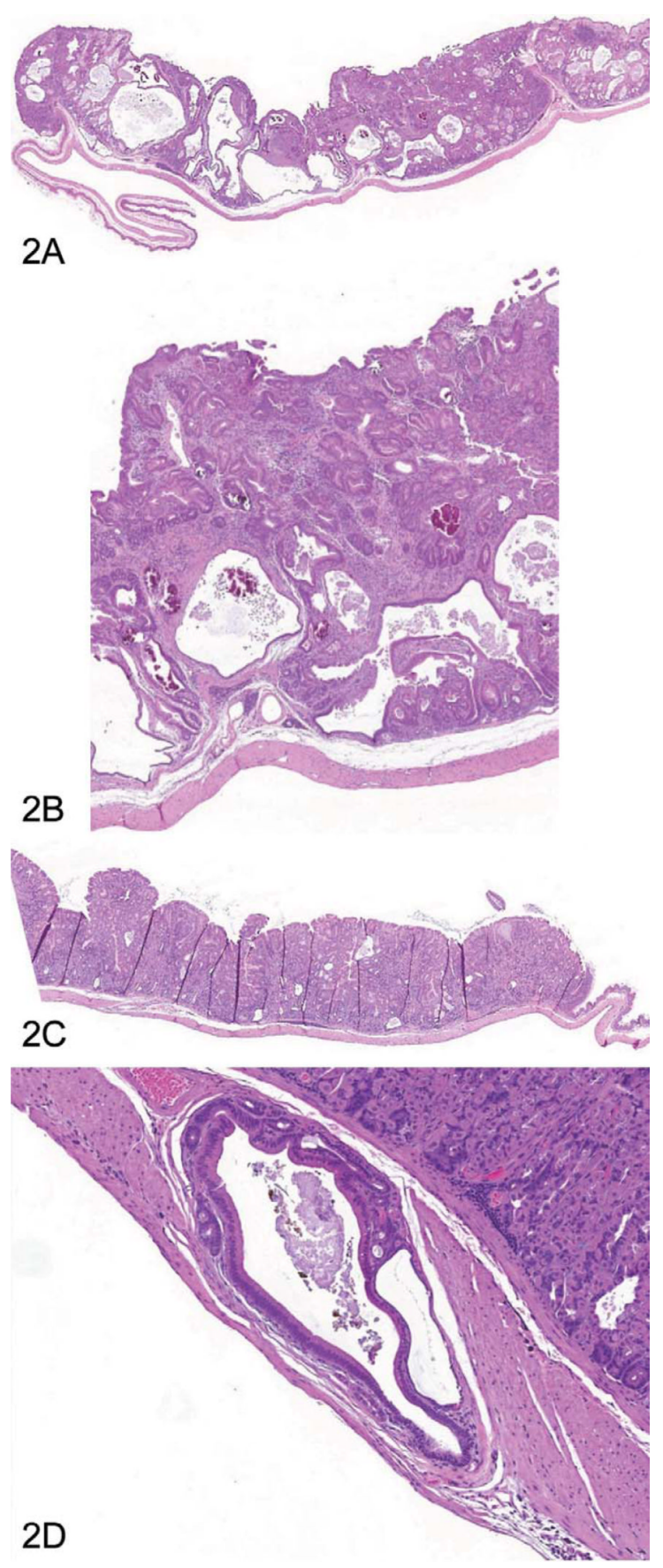

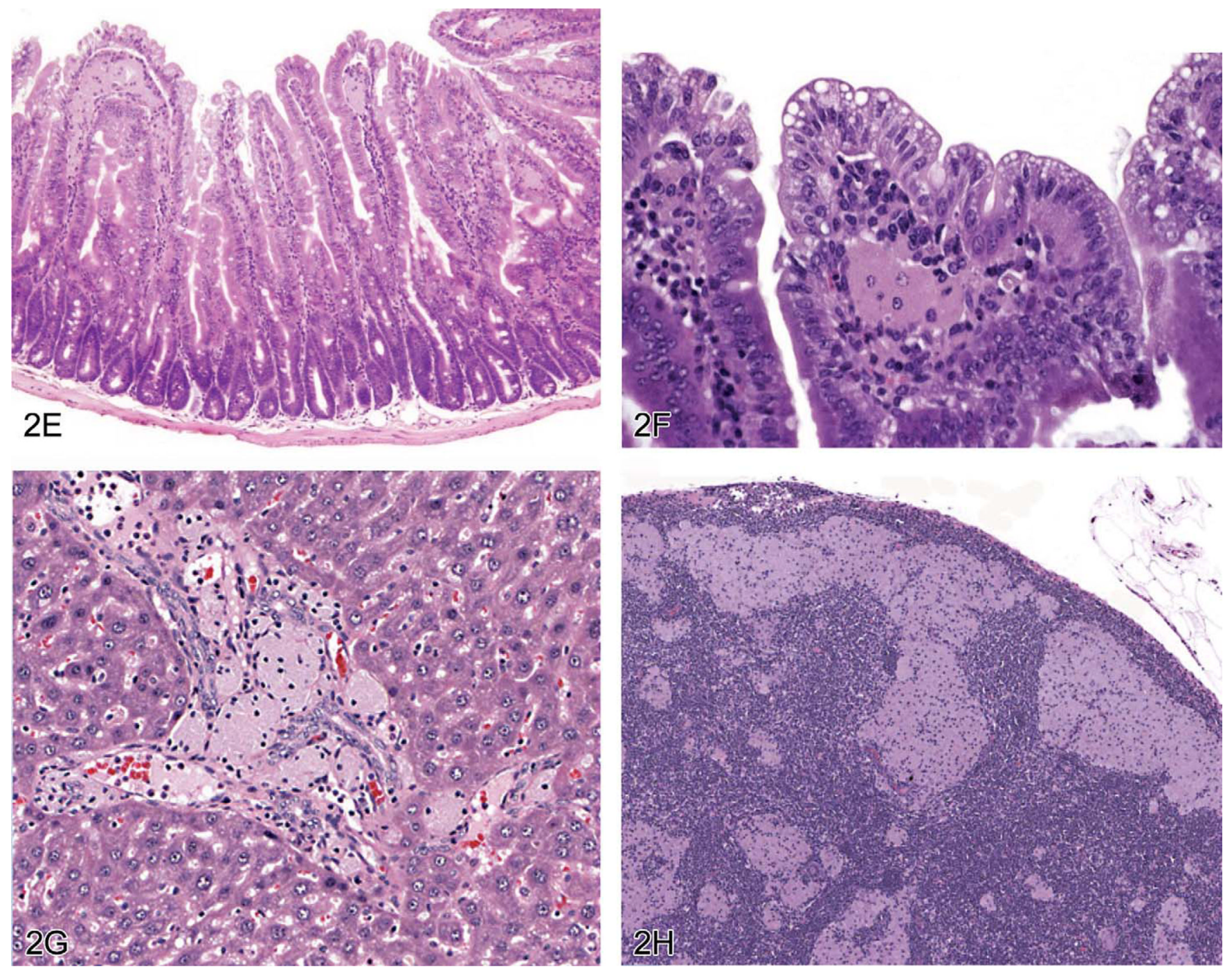

Figure 2. Lesions from the stomach of a CD1 mouse and the duodenum of a B6C3F1 mouse (A) Cystic hyperplasia of the glandular stomach in a CD1 mouse. (B) Higher magnification of the stomach lesion in (A) showing inflammation and mineralization. (C) Diffuse hyperplasia of the glandular stomach. (D) Herniation of the epithelium into the muscularis, with cyst formation. (E) Histiocytic aggregates within the villus interstitium in a sodium dichromate-treated mouse. (F) Higher magnification of (E). (G) Periportal accumulation of histiocytes in the liver of a sodium dichromate-treated mouse. (H) Histiocyte aggregates in the mesenteric lymph node of a sodium dichromate-treated mouse. All images are hematoxylin and eosin-stained sections. 

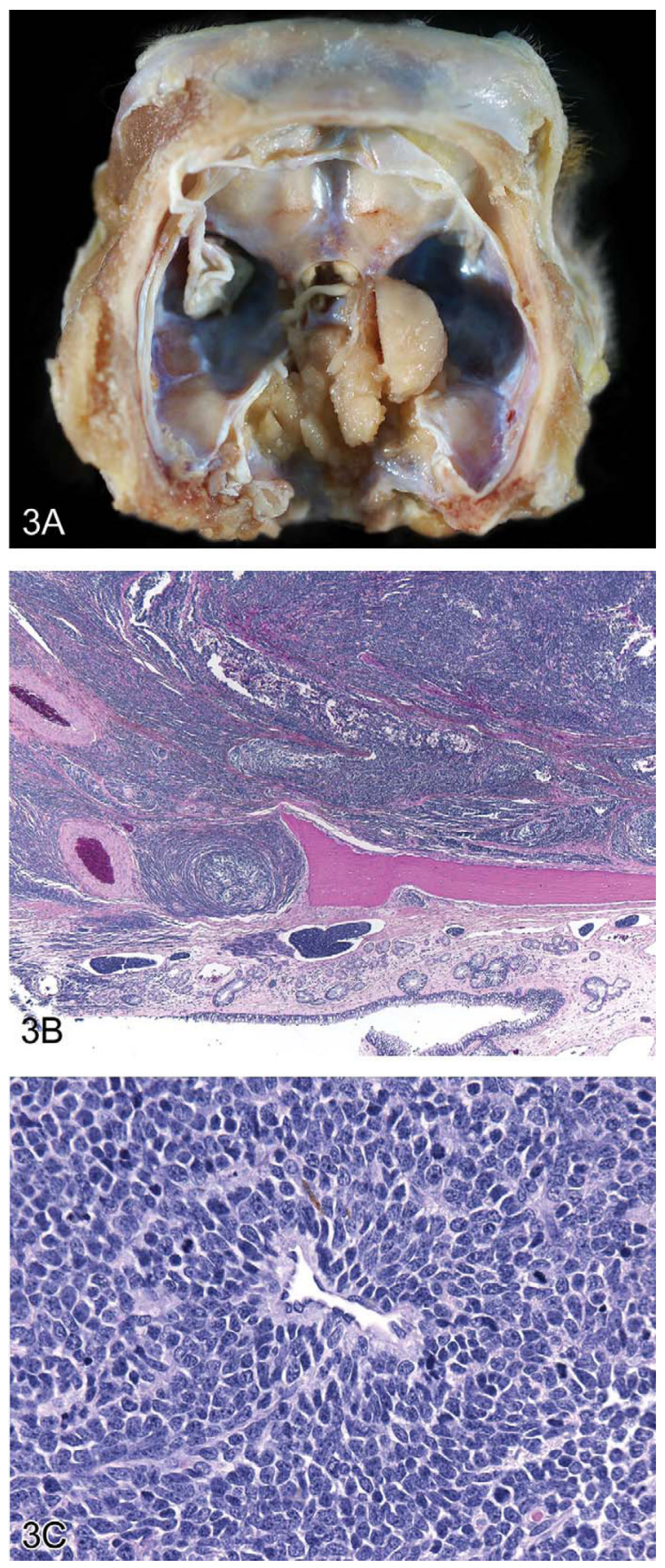

Figure 3. Olfactory neuroblastoma in a cynomolgus monkey

(A) Macroscopic view of the tumor at the base of the skull. (B) Low-magnification view of the tumor depicting neoplastic cells arranged in solid clusters, sheets, and lobules and separated by fine stroma. Hematoxylin and eosin. (C) High-magnification image of the tumor cells forming pseudorosettes (tumor cells around blood vessels). Hematoxylin and eosin. 

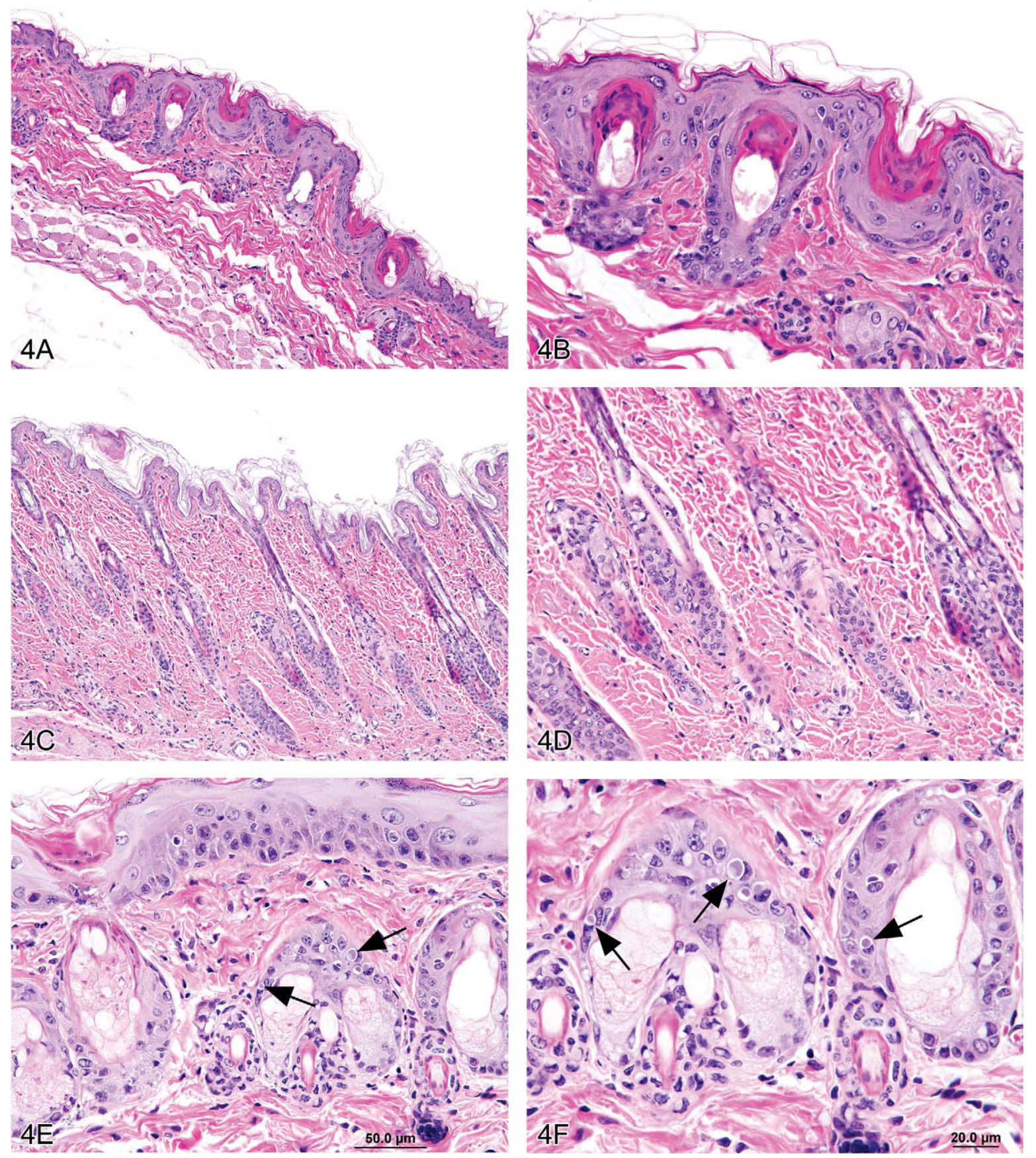

Figure 4. Skin lesions in rodents following subchronic, whole-body inhalation exposure to a compound under study by NTP

(A) Follicular epithelial parakeratotic hyperkeratosis in a high-dose male B6C3F1 mouse. Moderate epithelial hyperplasia is also present. (B) Higher magnification of (A). (C) Adnexal degeneration in a high-dose male HSD rat. (D) Higher magnification of (C). Note the lack of well-developed sebaceous glands, irregular/distorted hair follicles, and presence of increased pyknotic/karyorrhectic debris. (E) Intracytoplasmic accumulations in a highdose male B6C3F1 mouse (arrows). (F) Higher magnification of (E). Note that the intracytoplasmic accumulations often displace the nucleus and vary in size and tinctoral properties (arrows). All images are hematoxylin and eosin-stained sections. 

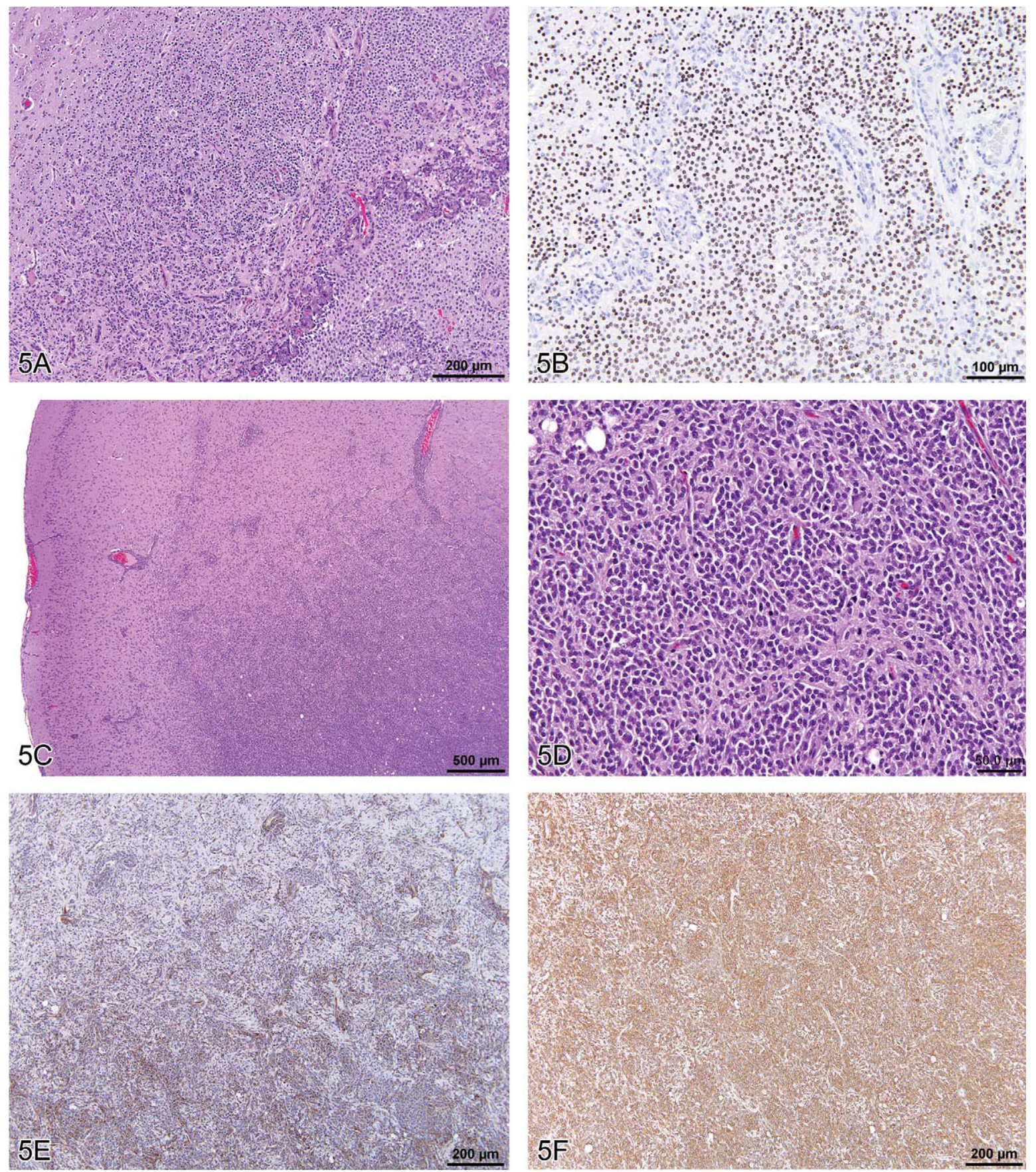

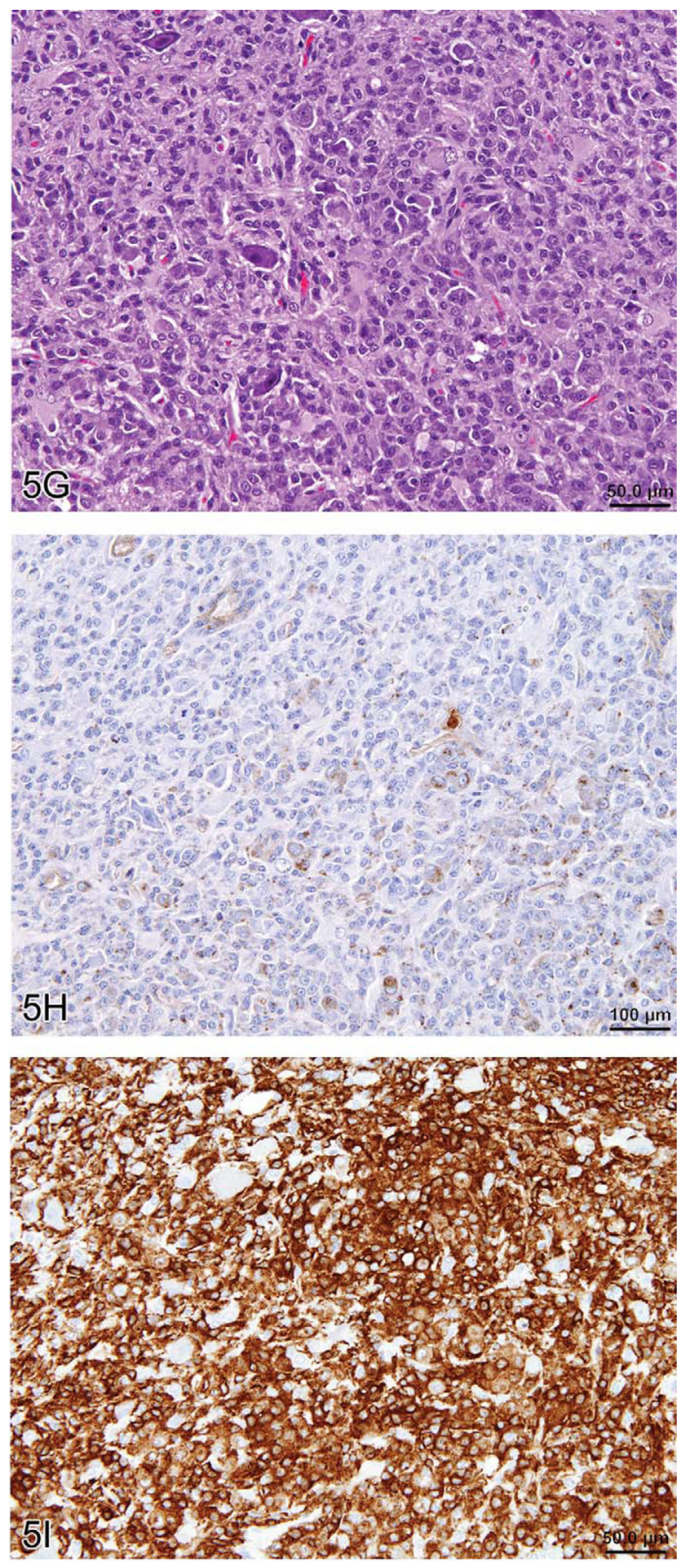

Figure 5. Rat brain neoplasms from chronic National Toxicology Program carcinogenicity studies

(A) A moderately well-demarcated spontaneous oligodendroglioma composed of small, uniformly sized cells. Hematoxylin and eosin (H\&E). (B) The neoplastic cells from Figure A show very strong and consistent staining with an Olig2 immunohistochemical marker. (C) Spontaneous microglioma showing diffuse parenchymal infiltration and, in some areas, neuronal satellitosis and perivascular cuffing. H\&E. (D) Higher magnification of (C) showing moderately sized neoplastic cells with indistinct cellular borders and round to elongate nuclei. Spontaneous microgliomas in this study showed strong and consistent staining with immunohistochemical markers for RCA-1 (E) and Iba-1 (F). Chemically 
induced microglioma $(\mathrm{G})$ with moderately sized round to elongated neoplastic cells with variably distinct borders. H\&E. (H) Chemically induced microglioma with reduced staining intensity for RCA-1. (I) Chemically induced microglioma with increased staining intensity for OX-6 (MHCII). 

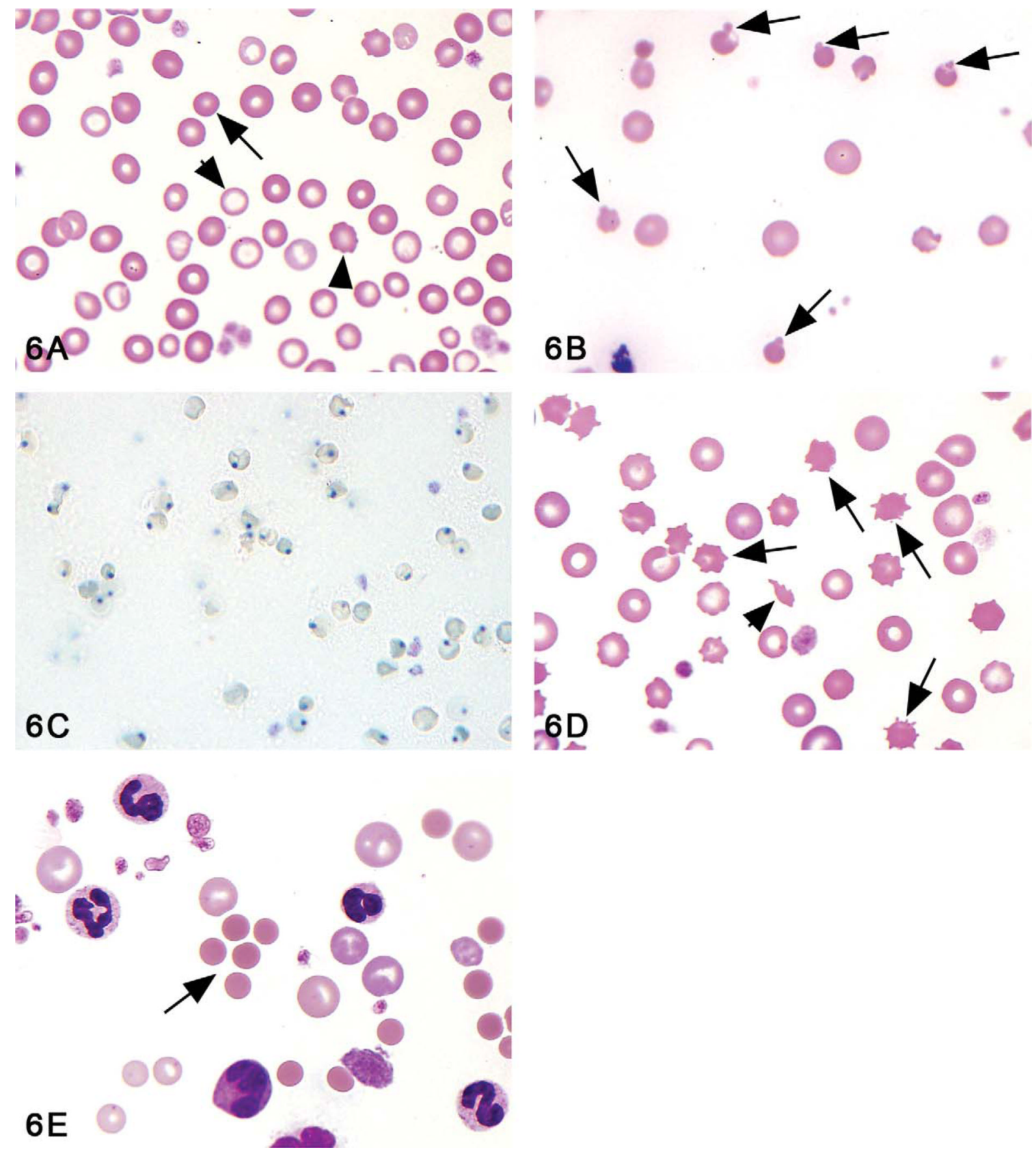

Figure 6. Examples of microcytes, Heinz bodies, poikilocytes, and spherocytes

(A) Dog, blood smear, Wright-Leishman stain. Notice the microcytes (long arrow), hypochromia (short arrow), and scattered poikilocytes (arrowhead) in the blood of a dog with iron deficiency anemia. (B) Horse, blood smear, Wright-Leishman stain. Multiple Heinz bodies (arrows) are present in this case of red maple toxicosis. Heinz bodies are small, round inclusions within the red cell body, though when stained with certain dyes, they appear as projections from the cell. (C) Horse, blood smear, red maple toxicosis, new methylene blue preparation with Wright counterstain. Notice the Heinz bodies that appear as dark blue spherical structures extending from the margin of the red blood cells. (D) Dog, blood smear, Wright-Leishman stain. Scattered poikilocytes in the blood of a dog with 
hemangiosarcoma. Note the shistocyte (short arrow) and multiple acanthocytes (long arrows). Angiopathy was associated with disseminated intravascular coagulation, but turbulent blood flow could not be excluded. (E) Dog, blood smear, Wright-Leishman stain. Immune-mediated hemolytic anemia with polychromasia and spherocytosis. Spherocytes appear as smaller erythrocytes that lack central pallor (arrow). 

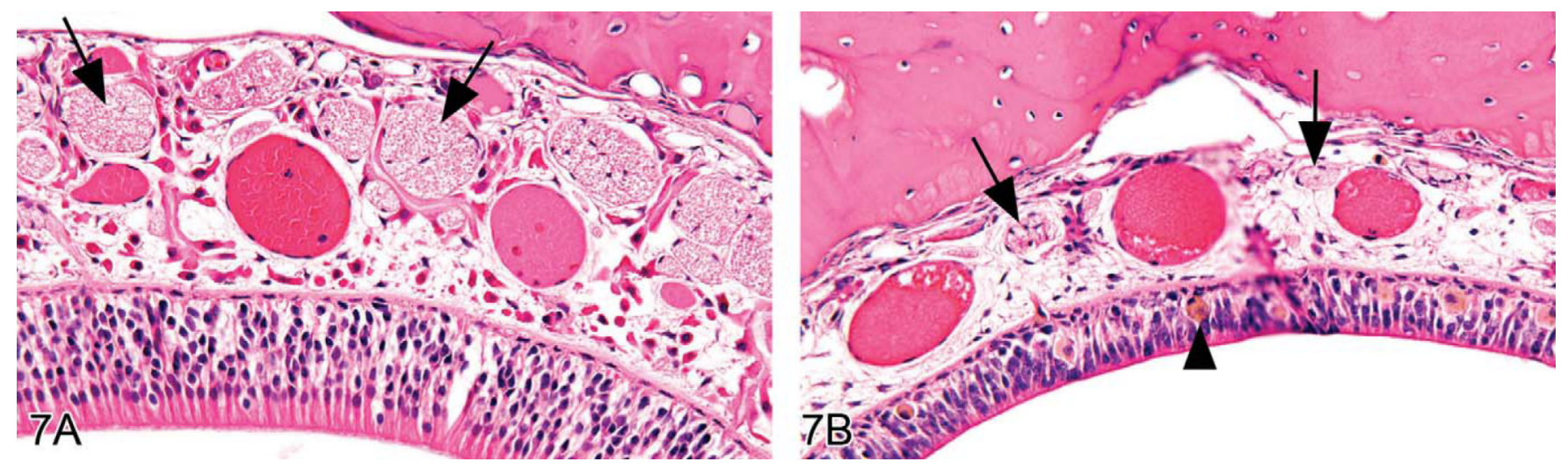

Figure 7. Nasal lesions in the rat

(A) Olfactory epithelium in the dorsal meatus of level II of the nasal cavity of a control rat from the NTP three-month green tea extract gavage study. Note normal size and number of the olfactory nerves in the lamina propria (arrows). Hematoxylin and eosin. (B) Olfactory epithelium atrophy, nerve fiber atrophy (arrows), and pigmented histiocytes (arrowhead) in the dorsal meatus of level II of the nasal cavity of a male rat administered with $1,000 \mathrm{mg} / \mathrm{kg}$ green tea extract by gavage for 3 months. Compare with Figure 7A. Hematoxylin and eosin. Reprinted with permission from Chan et al. 2010. 


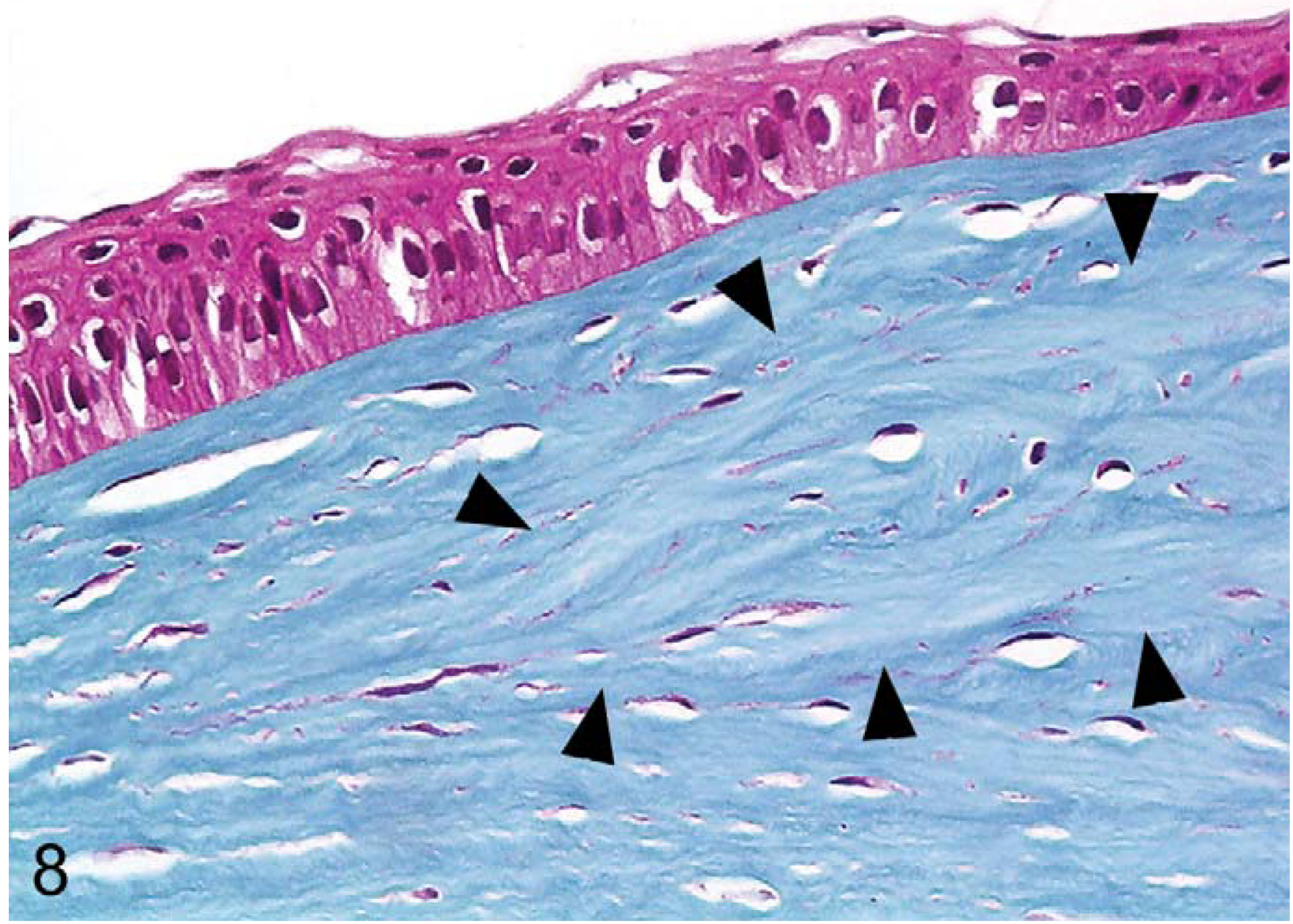

Figure 8. Superficial corneal dystrophy in a Dutch belted rabbit

The opacity consists of a discrete lesion (arrowheads) with epithelial thinning over the lesion and progressing to thickening at the edge with normal cornea. The affected stroma contains an increase in the number and size of keratinocytes with enhanced staining and irregularity in the stromal fibers. Masson's trichrome. 

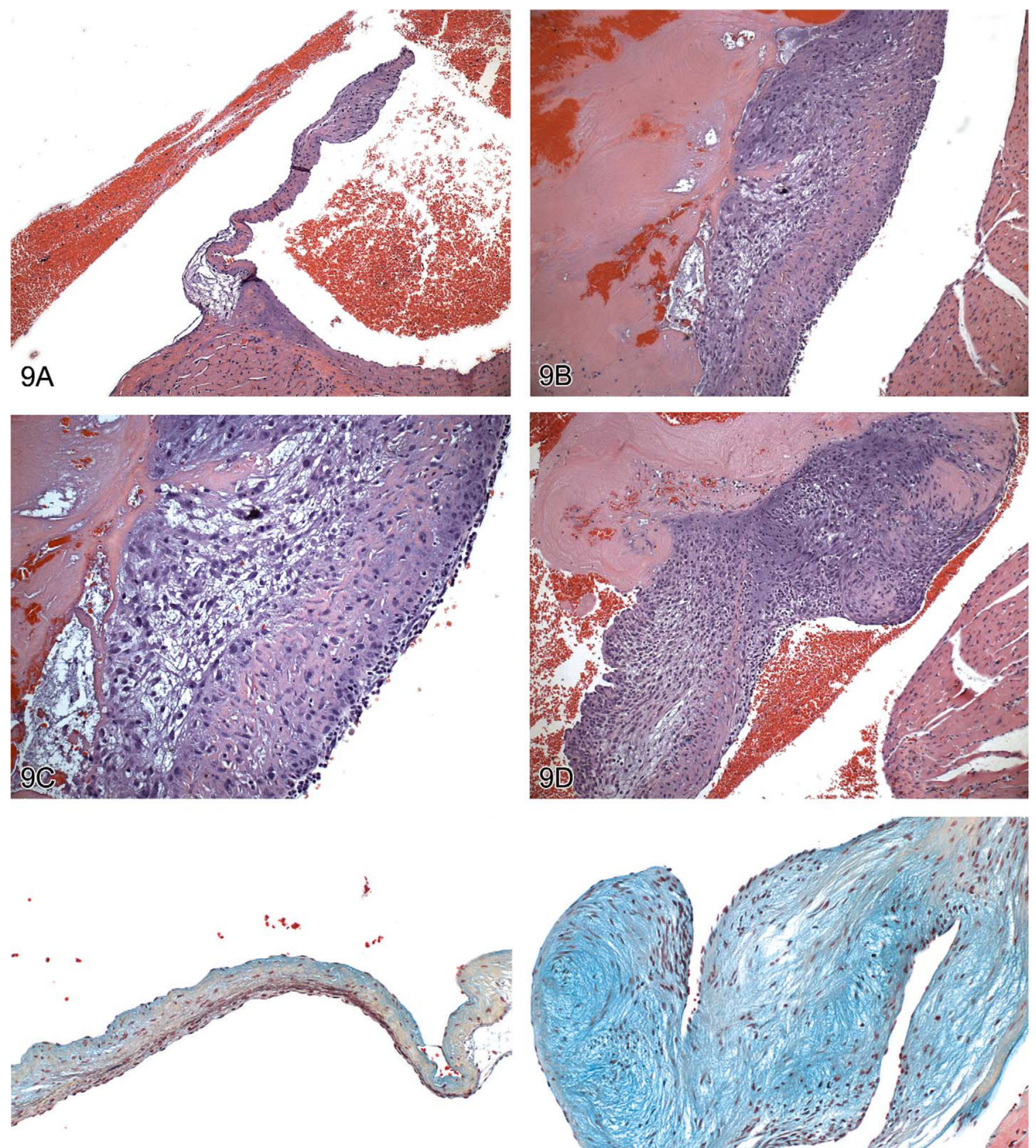

9E

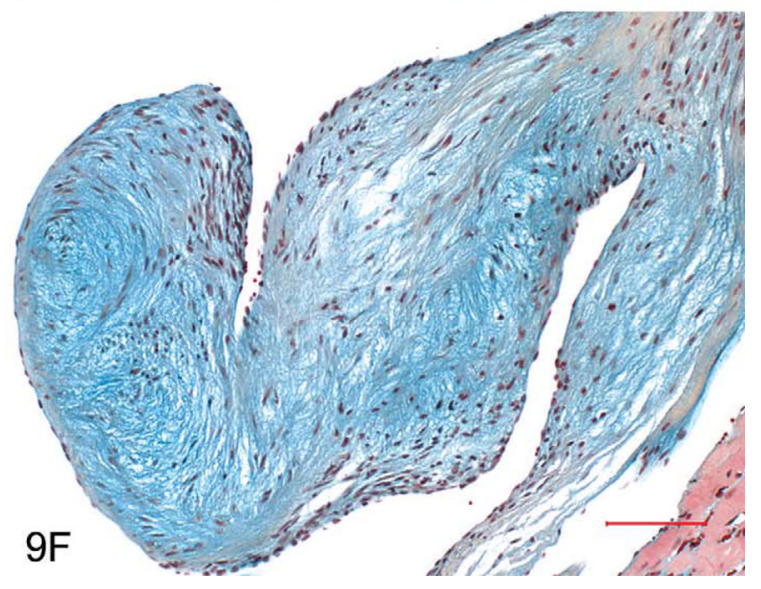

Figure 9. Heart valve lesions in the rat

(A) Control mitral heart valve showing the three layers, with the fibrosa on the right, the spongiosa in the middle, and the ventricularis on the left. Hematoxylin and eosin (H\&E). (B) High-dose rat mitral heart valve showing thickening of the endothelium in the ventricularis layer, with attached thrombus. The spongiosa (intermediate) and fibrosa (atrium) layer are not significantly affected by proliferation. H\&E. (C) Higher magnification of (B) showing detail of the ventricularis layer with a myxomatous proliferation of the endothelium.

Thrombus attachment is visible on the top left. H\&E. (D) Mitral valve from a high-dose rat showing a profuse proliferation of the endothelial ventricularis layer with no thickening of the spongiosa (intermediate) layer. The lack of thrombus involvement in the proliferative 
change on the left indicates that the proliferation of the endothelium precedes the formation of thrombosis; therefore, the term valvulitis is justified. H\&E. (E) Normal mitral valve leaflet from a Sprague Dawley rat compared to $(\mathrm{F})$, a markedly thickened mitral valve leaflet with spontaneous mitral valvulopathy. The glycosaminoglycan-rich fibromyxoid tissue is highlighted by Movat's pentachrome stain (Elangbam 2010). Reprinted with permission. 

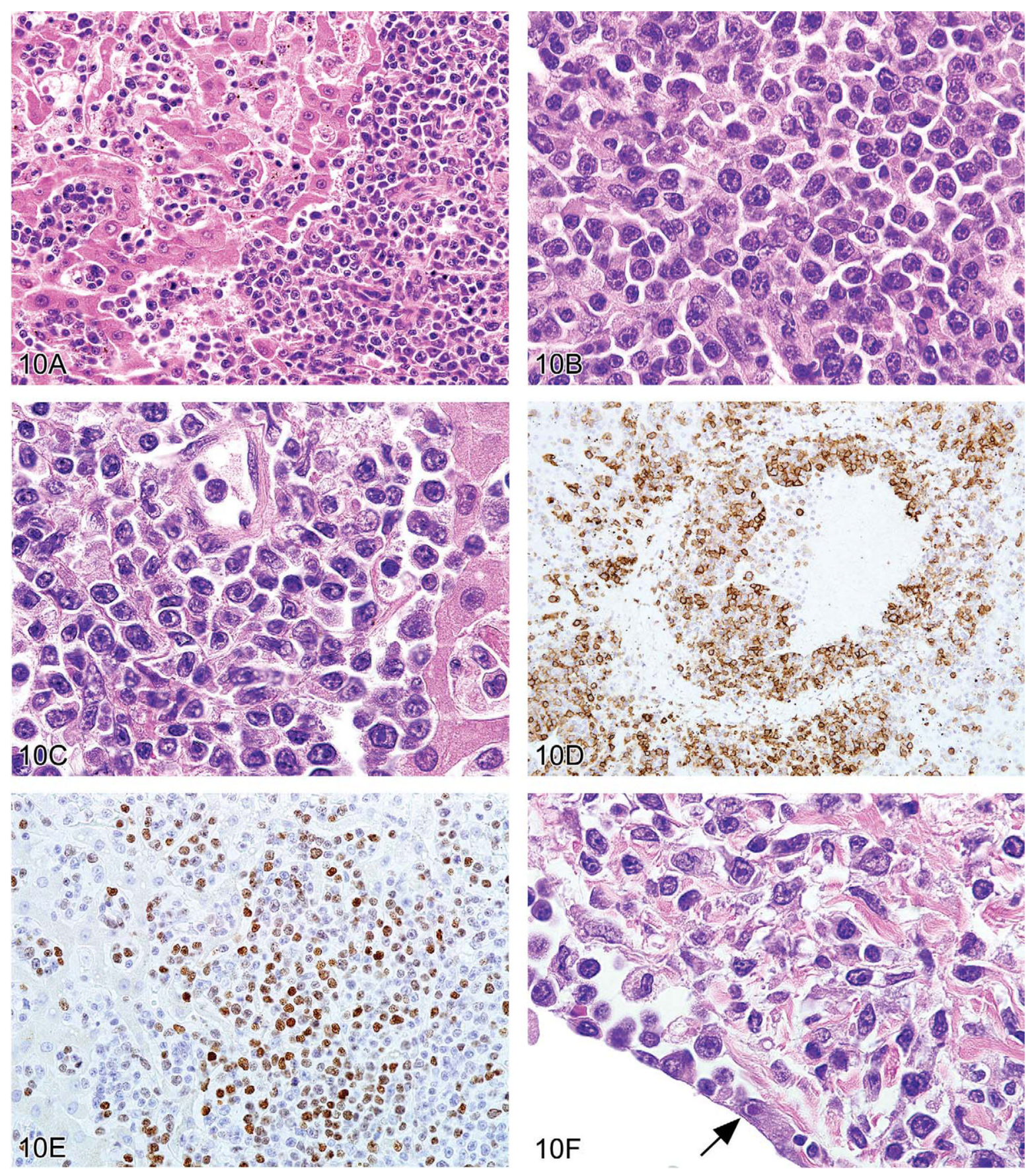

Figure 10. Post-transplant lymphoproliferative disease in a monkey

(A) Liver showing massive infiltration of immature lymphocytes. Hematoxylin and eosin (H\&E). (B) High magnification of lymph node showing mixture of immunoblasts,

plasmacytoid cells, and small lymphocytes. H\&E. (C) Liver infiltrate contains more blast cells, but also a mixture of other lymphoid cells. H\&E. (D) CD20 expression in a majority of the infiltrating cells in the liver. (E) Epstein-Barr nuclear antigen expression on many infiltrating lymphoid cells. (F) An intranuclear CMV inclusion in an endothelial cell and lymphoid infiltrate in kidney. H\&E. 


\section{Table 1}

Characterization of brain tumors using an immunohistochemical panel.

\begin{tabular}{lcll}
\hline Antibody & Abbreviation & Cells detected & Staining location \\
\hline Glial fibrillary acidic protein & & Cytoplasmic \\
Ionized calcium-binding adapter molecule-1 $b$ & Iba-1 & Microglia/macrophages & Cytoplasmic \\
Lectin Ricinus communis agglutinin type $1^{c}$ & RCA-1 & Microglia/macrophages and endothelial cells & Membrane and cytoplasmic \\
MHC class II & & Astrocytes and some ependymal cells & Membrane \\
Oligodendrocyte transcription factor $2^{e}$ & OX-6 & Antigen-presenting cells & Nuclear and cytoplasmic \\
Neurofilament & Olig2 & Oligodendrocytes & Cytoplasmic \\
\hline
\end{tabular}

${ }^{a}$ Anti-GFAP rabbit polyclonal antibody; DAKO, Carpinteria, CA.

${ }^{b}$ Anti-Iba-1 rabbit polyclonal antibody; Wako Chemicals, Richmond, VA.

${ }^{c}$ Vector Laboratories, Burlingame, CA.

${ }^{d}$ Mouse anti-rat MHCII/OX-6 antibody; AbD Serotec, Raleigh, NC.

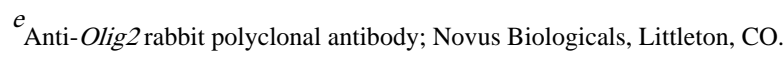

$f$ Mouse anti-human neurofilament primary antibody; DAKO, Carpinteria, CA 
Table 2

Causes of microcytosis detected via microscopic evaluation and/or automated hematology analyzers.

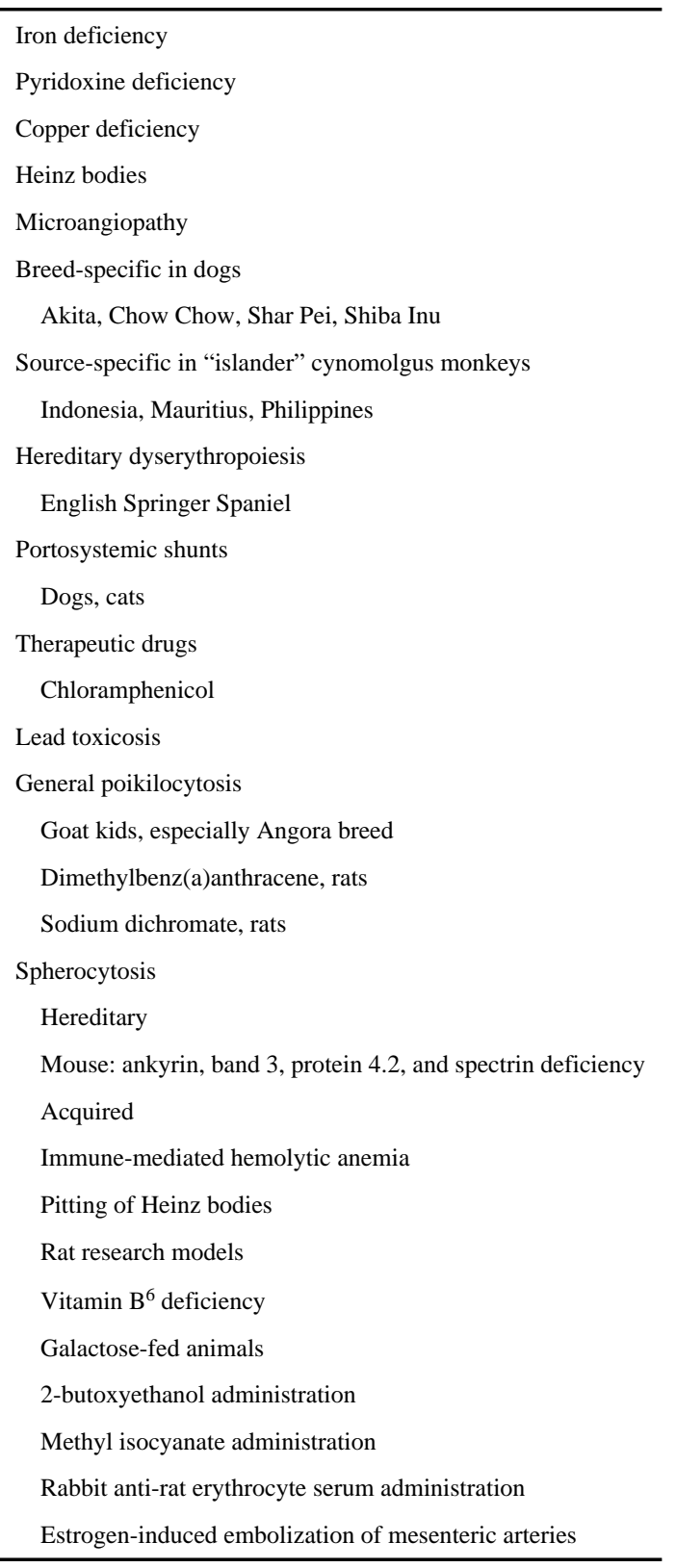




\section{Table 3}

Selected hematology data at day 23 for female rats in the ninety-day dosed-water study of sodium dichromate dihydrate. ${ }^{a}$

\begin{tabular}{|c|c|c|}
\hline Hematology & Control & $1000 \mathrm{mg} / \mathrm{L}$ \\
\hline Packed cell volume (\%) & 48.0 & $33.4^{*}$ \\
\hline Hematocrit (\%) & 47.7 & $19.5^{*}$ \\
\hline Hemoglobin (g/dL) & 15.9 & $9.7^{*}$ \\
\hline Erythrocytes $\left(10^{6} / \mu \mathrm{L}\right)$ & 7.82 & $4.21^{*}$ \\
\hline $\mathrm{MCV}(\mathrm{fL})$ & 61.1 & $46.5^{*}$ \\
\hline $\mathrm{MCHC}(\mathrm{g} / \mathrm{dL})$ & 33.3 & $49.6^{*}$ \\
\hline Reticulocytes (\%) & 2.7 & $5.1^{*}$ \\
\hline Reticulocytes $\left(10^{3} / \mu \mathrm{L}\right)$ & 210 & 220 \\
\hline $\mathrm{nRBC}\left(10^{3} / \mu \mathrm{L}\right)$ & 0.00 & $1.11^{*}$ \\
\hline
\end{tabular}

Abbreviations: $\mathrm{MCV}$, mean cell volume; $\mathrm{MCHC}$, mean cell hemoglobin concentration; $\mathrm{nRBC}$, nucleated erythrocytes. 